\title{
El papel desempeñado por geólogos e ingenieros de minas en la consolidación de la Arqueología prehistórica en España (1860-1970)
}

\author{
M. Ayarzagüena Sanz \\ Área de Historia de la Ciencias, Facultad de Medicina de Ciudad Real, Universidad de Castilla-La Mancha, \\ Camino de Moledores s/n, E-13071 Ciudad Real, España \\ Profesor.MASanz@uclm.es
}

\begin{abstract}
RESUMEN
La Geoarqueología, como disciplina científica, inicia sus primeros pasos en el último cuarto del siglo XX; sin embargo, tiene sus antecedentes en los orígenes mismos de la Arqueología prehistórica, a partir de 1860. En España la evolución de la Arqueología prehistórica y de la Geoarqueología han ido parejos a los del resto de Europa. España fue el tercer país del mundo, tras Francia e Inglaterra, donde la comunidad científica internacional reconoció la existencia de industria prehistórica y, asimismo, cuando la Geoarqueología, como disciplina científica independiente, se empezó a institucionalizar en Europa, en España tampoco quedó a la zaga. A lo largo del presente artículo se hace un estudio del desarrollo de los estudios prehistóricos en España desde mediados del siglo XIX hasta los años 70 del siglo XX mostrando la incidencia que los estudios geológicos han tenido en los mismos.
\end{abstract}

Palabras clave: Arqueología, Cuaternario, España, Geología, Historiografía.

\section{The role played by geologists and mining engineers in the consolidation of prehistoric archeology in Spain (1860-1970)}

\begin{abstract}
Geoarchaeology, as a scientific discipline, took its first steps in the last quarter of the twentieth century. However, its background lies in the very origins of prehistoric archaeology, from 1860 onwards. In Spain the evolution of Geoarchaeology and the studies that preceded it has kept pace with the rest of Europe. Spain was the third country in the world, after France and Britain, in which the international scientific community recognized the existence of prehistoric industry; similarly, when Geoarchaeology, as an independent scientific discipline, began to be institutionalized in Europe, Spain was not left behind. In this study we will examine the development of prehistoric studies in Spain from the mid-nineteenth century to the late twentieth, showing the effects that geological studies have had on them.
\end{abstract}

Keywords: Archaeology, Quaternary, Spain, Geology, Historiography.

\section{ABRIDGED ENGLISH VERSION}

\section{Introduction}

Geoarchaeology began in 1975 with the work of Shackley (1975). It is thus very recent, less than half a century old, and consequently has had a short and limited history. However, the origins of scientific archaeology are closely related to the development of geology, and the relationship between geology and archaeology was established from the very beginning of prehistoric science.

The method used in this study has been hermeneutic: the main purpose of this chapter is to approach, from a historiographical perspective, the development of the relationship between archaeology and geology in Spain, as well as the evolution of the academic and institutional structures within which it was conceived. 
Ayarzagüena Sanz, M., 2018. El papel desempeñado por geólogos e ingenieros de... Boletín Geológico y Minero, 129 (1/2): 13-33

\section{Geology and the beginnings of Prehistory in Spain}

The first prehistorians in Spain were mining engineers and geologists. Casiano de Prado is regarded as the first Spanish prehistorian because in 1862, together with the Frenchmen Louis Lartet and Édouard Verneuil, he discovered the first prehistoric tool in Spain (Fig. 1). Previously Prado, in 1850, after the discovery of the remains of an Elephas in San Isidro, had collected some carved Palaeolithic flints, one of which is still held in the museum of the School of Mines in Madrid (Figs. 2 and 3).

The successor of Prado was Juan Vilanova i Piera, Professor of Geology and Palaeontology at the Central University of Madrid. The intimate union between Geology and Prehistory was well illustrated from the outset in the chair that Vilanova held in the Ateneo de Madrid, that of Geology and Prehistory. Vilanova is responsible for one of the first reconstructions of palaeoenvironments, within a creationist perspective (Fig. 4).

With the entry of geology into archaeology came stratigraphy and palaeogeography. In fact, discussions about the strata in the Manzanares valley in which the San Isidro industry appeared continued throughout the nineteenth century. The stratigraphic section Vilanova included in his work Origen, Naturaleza y Antigüedad del Hombre (Origin, nature and antiquity of man) (Fig. 5), is noteworthy in that it was published in the late nineteenth century, but with data from mid-century, when the Elephas remains appeared, unearthed by Graells and Prado (Fig. 6).

\section{Spanish Prehistoric Archaeology in the first third of the Twentieth Century}

After the death of Vilanova in 1893 prehistoric studies came to a halt in Spain for some years. In the first decade of the twentieth century the recognition of the value of the paintings of Altamira brought about a collaboration between French and Spanish prehistorians that led to a series of discoveries in the caves of Cantabria. In 1910 the Prince of Monaco founded the Institut de Paléontologie Humaine in Paris (IPH), which initially concentrated its research on the cave of El Castillo (Puente Viesgo, Cantabria), to which there came researchers of international stature, such as Teilhard de Chardin. Training of local archaeologists such as the Count de la Vega del Sella (Fig. 8) was also encouraged.

In 1907 the Junta para Ampliación de Estudios e Investigaciones Científicas (JAE) (Board for Extension of Scientific Research and Studies) was set up, under the intellectual and ideological control of members of the Institución Libre de Enseñanza (ILE) (Free Institution of Education), and in which an important role was played by Eduardo Hernandez-Pacheco, professor of Geology in the University of Madrid from 1910.

In 1911 the General Law of Excavations was published, the first law relating to excavations enacted in Spain. Its main objective was to stop the looting which Spanish archaeological sites suffered, and in 1912 the Board of Excavations and Antiquities (JAE) was set up, as the body responsible for enforcing the General Law of Excavations.

The Paleontological and Prehistoric Research Commission (Spanish initials CIPP) was established in 1912 within the JAE, created to control prehistoric research carried out in this country. Other prominent members of the commission were Juan Cabré, Count de la Vega del Sella, Hugo Obermaier, Paul Wernert and Pedro Bosch Gimpera. The headquarters of the Commission were located in the Museum of Natural Sciences, focusing its work preferably on the Palaeolithic.

At the same time as the state institutions were being created, others were established in the outlying areas, such as Catalonia, where the Institut d'Estudis Catalans was founded in 1907. Bosch, after returning from Germany and being awarded the Chair of Ancient and Medieval History, began classes in the academic year 1915-1916. In this first year he had as a student, amongst others, Lluis Pericot.

In the following year, he would organize, on the German model, a Prehistory Seminar, from which would come some of the most important prehistorians of the first third of the century. The Seminar became a research centre in which the first great system of peninsular prehistory was established. For two decades, it set the orthodoxy for Spanish Prehistory, and its model of seminar was exported to other regions of Spain such as the Basque Country, Valencia and Madrid.

A significant change of course for Spanish prehistoric studies was the creation in 1922 of the Chair of Primitive History of Mankind in the Faculty of Philosophy and Letters, specifically for Obermaier.

\section{The Second Republic}

After the elections of April 1931, the Second Republic was declared. It brought a new air of freedom, more advanced teaching methods and greater optimism amongst the middle classes, in which the principles of the ILE were predominant. The Spanish Constitution of 1931 would be one of the most advanced in the protection of historical heritage, especially regarding the extent of the property to be protected, since it now incorporated cultural value. All this would be reflected in the Artistic Heritage Act of 1933. 
Ayarzagüena Sanz, M., 2018. El papel desempeñado por geólogos e ingenieros de... Boletín Geológico y Minero, 129 (1/2): $13-33$

The archaeological groups that had formed during the first third of the twentieth century became even more important in the Second Republic.

\section{Geology in its relationship with Archaeology in the Franco Era}

After the Spanish Civil War, the JSEA was replaced by the Comisaría General de Excavaciones Arqueológicas (General Commission for Archaeological Excavations), directed by Julio Martínez Santa-Olalla. The prosecution of all those who had any role with the Republic brought about an intellectual desert which, of course, had its repercussions on prehistoric studies.

At the organizational level, in 1939 the Consejo Superior de Investigaciones Cientificas (CSIC) (Superior Council for Scientific Research) was created, and took over the resources and part of the structure of the JAE. Prehistoric studies were not stimulated until the late 50s: in 1958 the Spanish Institute of Prehistory, which was the first state agency devoted entirely to prehistoric research, was created. Martin Almagro Basch was to be its first director, a role which he would combine with the Chair of Early History of the Central University of Madrid that he had obtained in 1954. Thereafter Martin Almagro was to play a leading role in Spanish Prehistory until 1981- that is, after the arrival of democracy in Spain.

After the Civil War, along with the purging of many prehistorians who had remained in Spain (as was the case of Enrique Eguren or Francisco Jordá) all regional institutions that existed during the Republic were dismantled or transformed.

In Catalonia, Bosch Gimpera had to go into exile. Pericot underwent a process of purification, but continued in his chair, where he served as the teacher of Joan Maluquer, Miquel Tarradell, Eduard Ripoll, Antonio Arribas, among others - in other words, of a large number of the most important prehistorians of the second half of the twentieth century.

There was a shift in prehistoric studies in the mid-50s when the General Commission for Archaeological Excavations was dissolved. In its place there was a National Service for Archaeological Excavations, in which university professors began to carry greater weight in the management of archaeology, leading to greater professionalism and specialization.

The IV Congress of the International Union for Prehistoric and Protohistoric Sciences (IUPPS) was held in Madrid in 1954 and marked the new international stance of Franco's regime towards Archaeology after the beginning of the Cold War. Similarly the $V$ Quaternary Congress organized by the International Union for Quaternary Science (INQUA) in 1957 would give a boost to studies on the Palaeolithic in Spain.

If the sixties can be seen as the time of the consolidation of Spanish Archaeology, the period from the early 70 s onwards may be characterized as that of development, expansion and final institutionalization. New academic chairs, an increase in teaching staff and an exponential increase in the number of students made this development possible. Likewise, many provincial museums would have their own research programmes.

\section{Introducción}

La Geoarqueología como tal es una rama del saber muy novedosa. Se inicia a partir de 1975 con trabajos de Shackley (1975). Y será a partir del año siguiente, en 1976, cuando, tras el apoyo de Colin Renfrew, la Geoarqueología sea admitida por la comunidad científica internacional, y muy especialmente por los arqueólogos. De hecho algunos fijan su nacimiento en 1976 (Goldberg and Macphail, 2006), cuando Colin Renfrew definía el término de esta manera: "This new discipline of geoarchaeology is primarily concerned with the context in which archaeological remains are found. And since archaeology, or at least prehistoric archaeology, recovers almost all of its basic data by excavation, every archaeological problem starts as a problem in geoarchaeology" (Renfrew, 1976). Esto implica que para la contextualización arqueológica, especialmente la relativa a la Arqueología prehistóri- ca, deben valorarse muy especialmente las aportaciones que puede ofrecer la Geoarqueología.

Así las cosas, en sentido estricto esta nueva disciplina es muy reciente, tendría menos de medio siglo $y$, consecuentemente, contaría con escasa y corta historia. Sin embargo, hay que reconocer que los orígenes de la Arqueología científica se encuentran íntimamente relacionados con el desarrollo de la Geología (Pollard, 1999:7), y esas relaciones entre la Geología y la Arqueología se establecieron desde el origen mismo de la ciencia prehistórica. Estas concomitancias iniciales, Pollard (1997-8) las personifica en Charles Lyell (1797-1875), quien además de fijar las bases de la Geología moderna en sus Principios de Geología (1830-1833), publicaría en 1863 Las evidencias geológicas de la Antigüedad del Hombre, justo cuando la Ciencia prehistórica estaba iniciando su consolidación y reconocimiento institucional.

El objetivo de este trabajo es plantear desde una 
perspectiva historiográfica el desarrollo de las relaciones Arqueología - Geología en nuestro país, así como el desarrollo de las estructuras académicas e institucionales en la que se gestó. Por supuesto, mencionando a aquellas personas que realizaron las investigaciones más relevantes y a las instituciones que las promovieron desde los inicios de la Arqueología prehistórica en el siglo XIX hasta el final del Franquismo.

\section{La Geología y los inicios de la Prehistoria en España}

No es casualidad que los primeros prehistoriadores en España fueran ingenieros de minas o geólogos. A Casiano de Prado y Vallo (1797-1866) se le considera como el primer prehistoriador español, pues gracias a él, en compañía de los geólogos Louis Lartet (18401899) y de Édouard Verneuil (1805-1873), se descubrió el 30 de abril de 1862 el primer útil prehistórico que fue calificado como tal por parte de la comunidad científica internacional (Figura 1), entrando así España, junto con Francia y Reino Unido, entre las naciones en las que se reconocía la existencia de culturas prehistóricas.

Las relaciones de los ingenieros de minas con la Geología venían de lejos. Una vez que se expande por Europa la Revolución Industrial, durante el siglo XIX se hace necesaria la prospección de minerales por todo el mundo y España pasa a ser suministradora de materias primas para la industria Europea. En ese contexto, la Escuela de Ingenieros de Minas pasa de Almadén a Madrid en 1835. Junto con el hecho de que poco antes se hubiera creado el Cuerpo de Ingenieros de Minas, se considera este momento como el de la institucionalización de la Geología en España (Pelayo, 1999: 31). Sin embargo, había un arduo problema. Por el decreto de 4 de enero de 1834 relativo a la ley de imprenta se restringían las publicaciones de libros y revistas considerados heterodoxos, de tal forma que la Geología fue sometida a censura religiosa (Sequeiros, 2011). En ese contexto, Prado, de espíritu progresista para su tiempo y fiel a su talante liberal, en 1835 escribe un folleto intitulado Vindicación de la Geología, frente a los que la despreciaban y atacaban tildando a esa disciplina de heterodoxa y anticristiana, pues ya se entreveía que profundizar en este campo implicaría a la larga alterar la verdad asumida sobre la Creación por la Biblia o, al menos, la interpretación que sobre esos textos era asumida. En un principio los estudios prehistóricos dejarían evidentes contradicciones sobre la Creación en general $y$, posteriormente, sobre la aparición del ser humano sobre la Tierra, lo que resultaba aún más

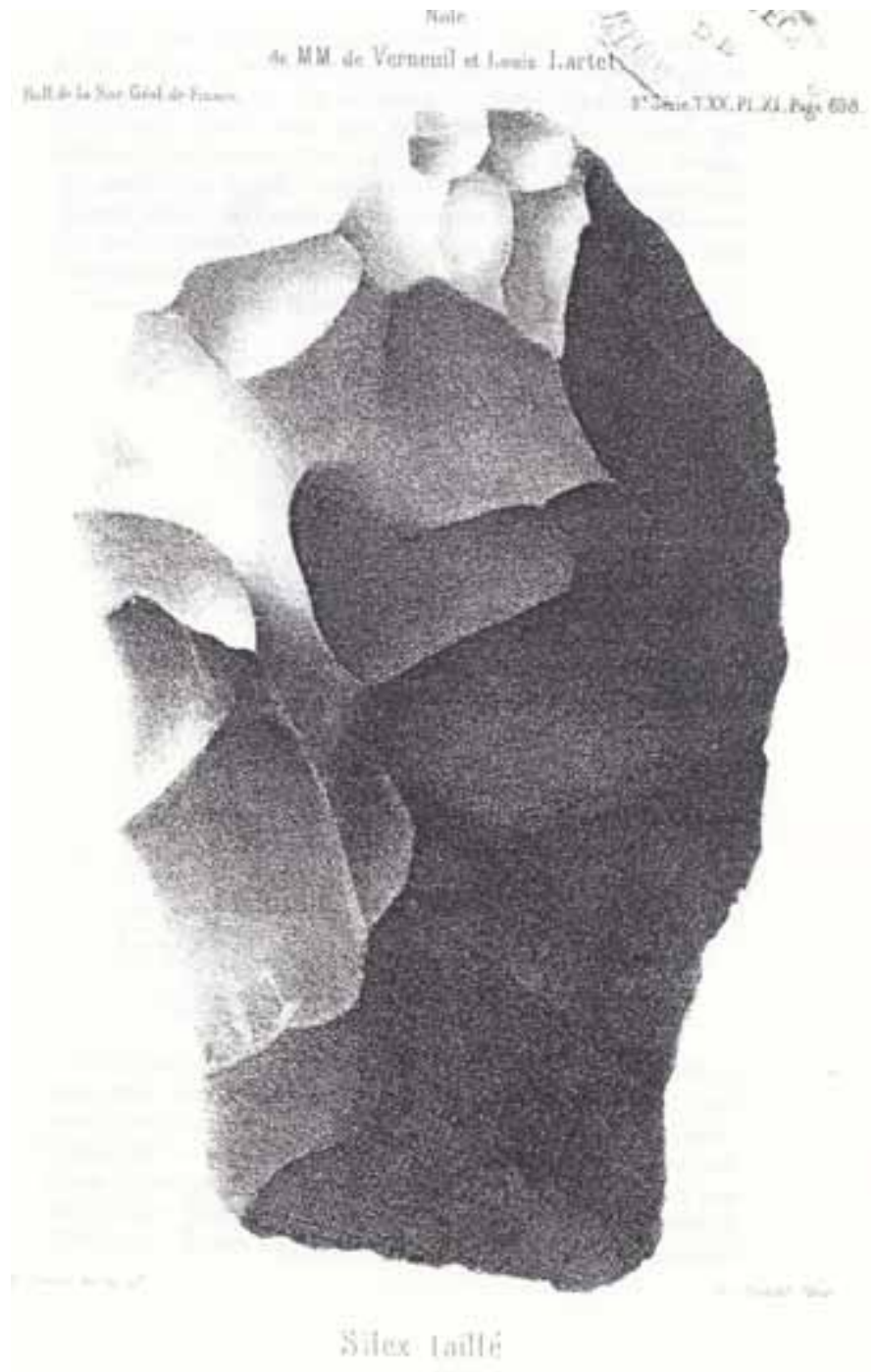

Figura 1. Pieza encontrada por Lartet, Verneuil y Prado en 1862 y que motivó el reconocimiento de la existencia de un yacimiento prehistórico en España. Actualmente se encuentra expuesta en el Museo de Saint Germain-en-Laye (Verneuil and Lartet, 1863).

Figure 1. Piece found by Lartet, Verneuil and Prado in 1862 which was the reason for recognizing the existence of a prehistoric site in Spain. It is currently exhibited at the Museum of Saint Germain-enLaye (Verneuil and Lartet, 1863).

grave. Más valor tiene, si cabe, la publicación de este librito de Prado, si tenemos en cuenta que Donato García (1782-1855), discípulo y sucesor de Christian Herrgen (1765-1816), no pudo publicar su Tratado de Geología (Vernet, 1975:219-220).

Casiano de Prado mantenía buenos contactos con geólogos y antropólogos franceses, como Eduardo Lartet (1801-1871) o Pruner Bey (1808-1882), quienes le motivaron hacia los estudios prehistóricos y le facilitaron su ingreso y reconocimiento en sociedades 
tan importantes como la Sociedad Geológica de Francia. En el año 1850, con motivo de las investigaciones que había realizado en San Isidro, tras el hallazgo de los restos de un Elephas, Casiano de Prado, recogió unos sílex tallados paleolíticos que apreció en buena medida, pues los llegó a siglar y uno todavía se encuentra depositado en el Museo de la Escuela de Minas de Madrid (Figuras 2 y 3 ) (Prado, 1864: 189 y Ayarzagüena, 2004: 23).

Pues bien, a partir del descubrimiento de 1862 Prado publicaría Descripción Física y Geológica de la Provincia de Madrid (Prado, 1864), donde aportaba interesantes informaciones sobre los descubrimientos prehistóricos en San Isidro, así como una "Noticia sobre Cavernas y Minas Primordiales en España" donde aportaba información sobre alguna cueva donde podría haber restos prehistóricos, y, sobre todo, unas "Breves reflexiones sobre la antigüedad del Hombre, y su supremacía entre los demás seres" en donde ya habla de la posibilidad de la existencia de una Edad del Cobre anterior a la del Bronce (Prado, 1864: 200), adelantándose así a muchos prehistoriadores del momento (Ayarzagüena and Puche, 2012). También distinguía las dos edades de la piedra, que no tendrían nombre (Paleolítico y Neolítico) hasta el año siguiente, 1865, cuando así las denominara

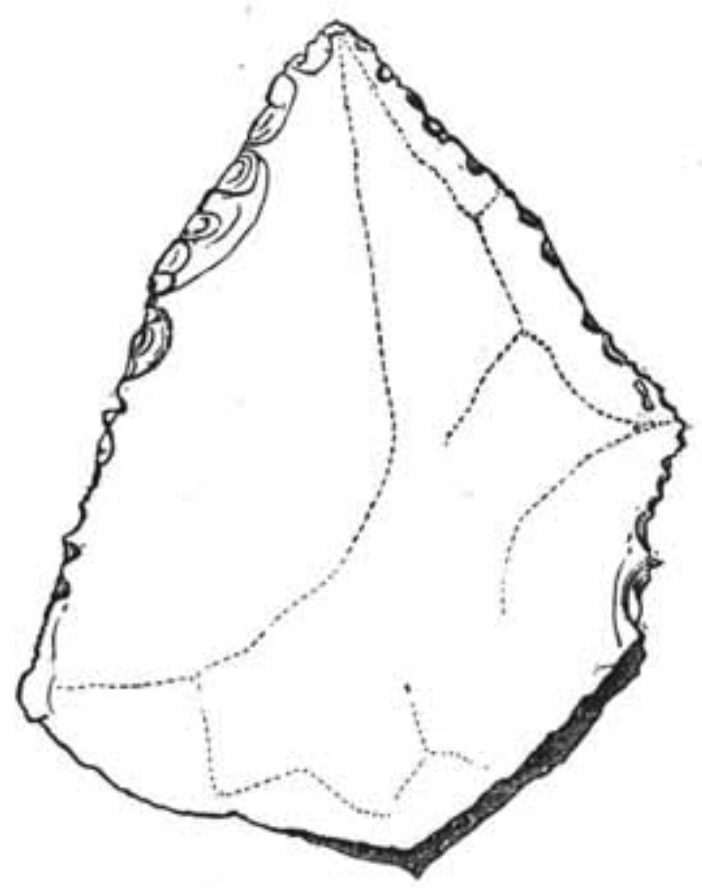

Figura 2. Pieza encontrada en 1850 en San Isidro por Casiano de Prado (Prado, 1864: 189).

Figure 2. Piece found in 1850 in San Isidro by Casiano de Prado (Prado, 1864: 189).
John Lubbock (1834-1913). Todo ello nos está hablando de un prehistoriador que estaba en la vanguardia sobre este tipo de estudios, los cuales los relacionaba directamente con los estudios geológicos.

Gran resonancia tendría la "Circular de la Comisión Permanente de Geología Industrial, dirigida a los ingenieros de minas, Jefes de las Provincias" de 1 de abril de 1865, que elaboró Casiano de Prado (Prado, 1865), como Vicepresidente, y en la que animaba a los ingenieros de minas a estudiar los restos prehistóricos y de la Antigüedad. Afirmaba (Prado, 1865: 252): "La geología, que bien considerada no se puede mirar sino como historia de la Tierra, se enlaza en sus últimos periodos con los pueblos que la habitan o habitaron. Preciso es por tanto buscar todos los

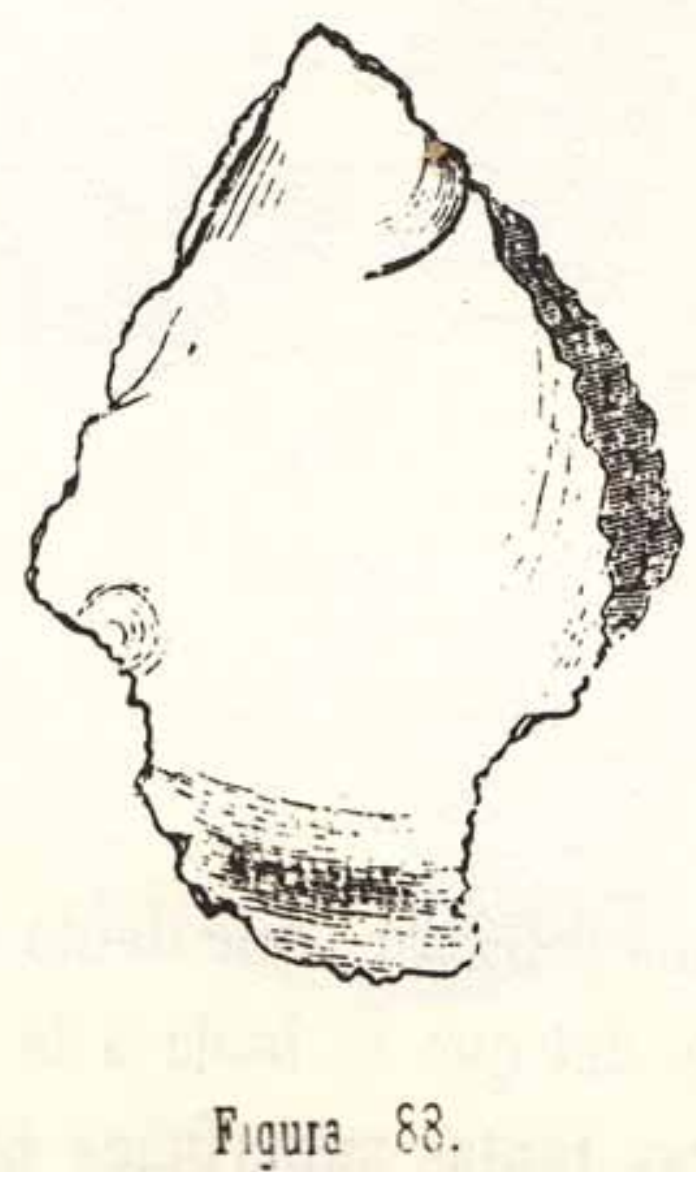

Figura 3. Pieza encontrada en San isidro en 1850 por Casiano de Prado. Actualmente se encuentra expuesta en el Museo Histórico de la Escuela de Minas de Madrid (Prado, 1864: 189).

Figure 3. Piece found in San Isidro in 1850 by Casiano de Prado. It is currently on display in the Historical Museum of the School of Mines of Madrid (Prado, 1864: 189). 
Ayarzagüena Sanz, M., 2018. El papel desempeñado por geólogos e ingenieros de... Boletín Geológico y Minero, 129 (1/2): 13-33

indicios que manifiesten la presencia del hombre en los tiempos de que no hay memoria, y aunque no sean tan antiguos. Deben buscarse sobre todo las piedras que sirvieron de armas y de utensilios conocidas con el nombre de piedras de rayo, centellas $y$ otros, correspondientes a la segunda edad de piedra y las de la que la precedió y no tuvieron nombre hasta ahora...".

Casiano de Prado moriría al año siguiente, en 1866, dejando un ambiente científico en España bien caldeado en pro de la Prehistoria (Puche and Ayarzagüena, 1997), al menos en determinados medios, y el testigo en los estudios prehistóricos en España dejado por Prado lo recogería Juan Vilanova y Piera (1821-1893), catedrático de Geología y Paleontología de la Universidad Central desde 1852. Sin embargo, Vilanova no mantuvo buenas relaciones con Prado (Rábano, 2006), subyaciendo de fondo entre ambos una lucha corporativa ente ingenieros de minas y geólogos. Esta lucha ente geólogos e ingenieros de minas en España la analizan Francisco Pelayo y Rodolfo Gozalo en el capítulo V.3 (Conflictos de intereses: Vilanova versus ingenieros de minas) de su estudio sobre Juan Vilanova (Pelayo and Gozalo, 2012). Vilanova mostró escaso interés por la Prehistoria en un primer momento, lo que criticaba Prado (Rábano, 2006: 426), y es que prácticamente hasta 1865 , es decir un año antes de la muerte de Casiano de Prado, Vilanova no mostró ninguna disposición favorable hacia el estudio sobre el origen del ser humano, estudios de los que fue su adalid a partir de 1866. Se considera que Vilanova dio el primer paso a favor de la Prehistoria cuando ayudó a crear la Sociedad Antropológica Española en 1865, siendo los temas relativos al origen del ser humano uno de los objetos de estudio de la sociedad que se propusieron desde un primer momento. Gran divulgador de la Prehistoria tanto en España como en el extranjero desde 1866, acudió a muchos de congresos internacionales, especialmente a los de Prehistoria y Geología. Esa unión íntima entre Geología y Prehistoria en un primer momento quedó bien de manifiesto en la cátedra que Vilanova ostentó en el Ateneo de Madrid, sobre Geología y Prehistoria, y que a partir del curso 1866-1867, y durante más de quince años, tuvo una especial inclinación hacia la ciencia prehistórica. Tuvieron especial reconocimiento en su momento las visitas de prospección a San Isidro que al final de cada curso Vilanova hacía con sus alumnos del Ateneo. A Vilanova se debe una de las primeras reconstrucciones de Paleoambientes dentro de una perspectiva creacionista (Fig. 4).

A partir de ese año, si bien coincidieron en el desarrollo de la Prehistoria diversas corrientes (geólo- gos, anticuarios, arquitectos, etc.), serán los geólogos $y$, por extensión, los naturalistas e ingenieros de minas quienes lleven a cabo la labor más rigurosa en este nuevo campo. Una muestra de la importancia que estaba tomando la Geología en los estudios prehistóricos la tenemos en relación con las reseñas que en su momento se escribieron con el primer libro en español que en su título lleva el término Prehistoria, debido a la pluma de Manuel de Góngora y Martínez (1822-1884). Esta obra fue Antigüedades prehistóricas de Andalucía (Góngora, 1868), obra encomiable en muchos aspectos, como la de haber sido organizada desde un planteamiento multidisciplinar. Realizada desde el paradigma erudito, tuvo grandes elogios de los historiadores del momento, siendo publicada con ayuda institucional del Ministerio de Fomento, tras informe favorable de la Real Academia de la Historia. Si bien también tuvo severas críticas. Una de ellas fue del naturalista Antonio Machado y Núñez (1815-1896), el abuelo de los famosos poetas. Machado criticaba la falta de formación geológica de Góngora, lo que le impedía hacer dataciones relativas (en ese momento los métodos para las dataciones numéricas eran muy rudimentarios, prácticamente inexistentes) (Machado, 1869: 37). Machado daba una auténtica lección sobre la importancia de la Geología para los estudios prehistóricos, justo cuando la Prehistoria estaba dando sus primeros pasos: "la obra del señor Góngora produce una impresión desagradable y un doloroso sentimiento; $y$ en efecto, ignoramos por sus descripciones si las grutas o cavernas adonde se han hallado los variados objetos de antiquísimas generaciones, pertenecían a depósitos de naturaleza distinta; cuál era la antigüedad relativa de los terrenos donde se han hallado yacían los útiles, instrumentos, huesos y demás materiales de la industria primitiva de aquellos habitantes; pues interpolados en su explicación, sin orden cronológico ni conocimiento de las rocas en su estratificación y estructura, no es posible determinar la época en que tuvieron lugar o el periodo geológico a que deben referirse".

Los prehistoriadores que, como Francisco $M$. Tubino (1833-1888), no tenían formación como naturalistas, destacaban la importancia de la Geología en los estudios prehistóricos. Por ello, en el siglo XIX, quienes en nuestro país se decantaron por los estudios prehistóricos fueron mayoritariamente naturalistas como Ildefonso Zubía (1819-1891), José Joaquín Landerer (1841-1922), Francisco Cánovas (1820-1904), el ya mencionado Machado, o Marcelino Sanz de Sautuola (1831-1888). Pero será el ingeniero de minas Luis Siret (1860-1934), a partir de 1881 en compañía de su hermano Enrique (1857-1933), y luego ya solo, quien realice unos descubrimientos arqueológicos 


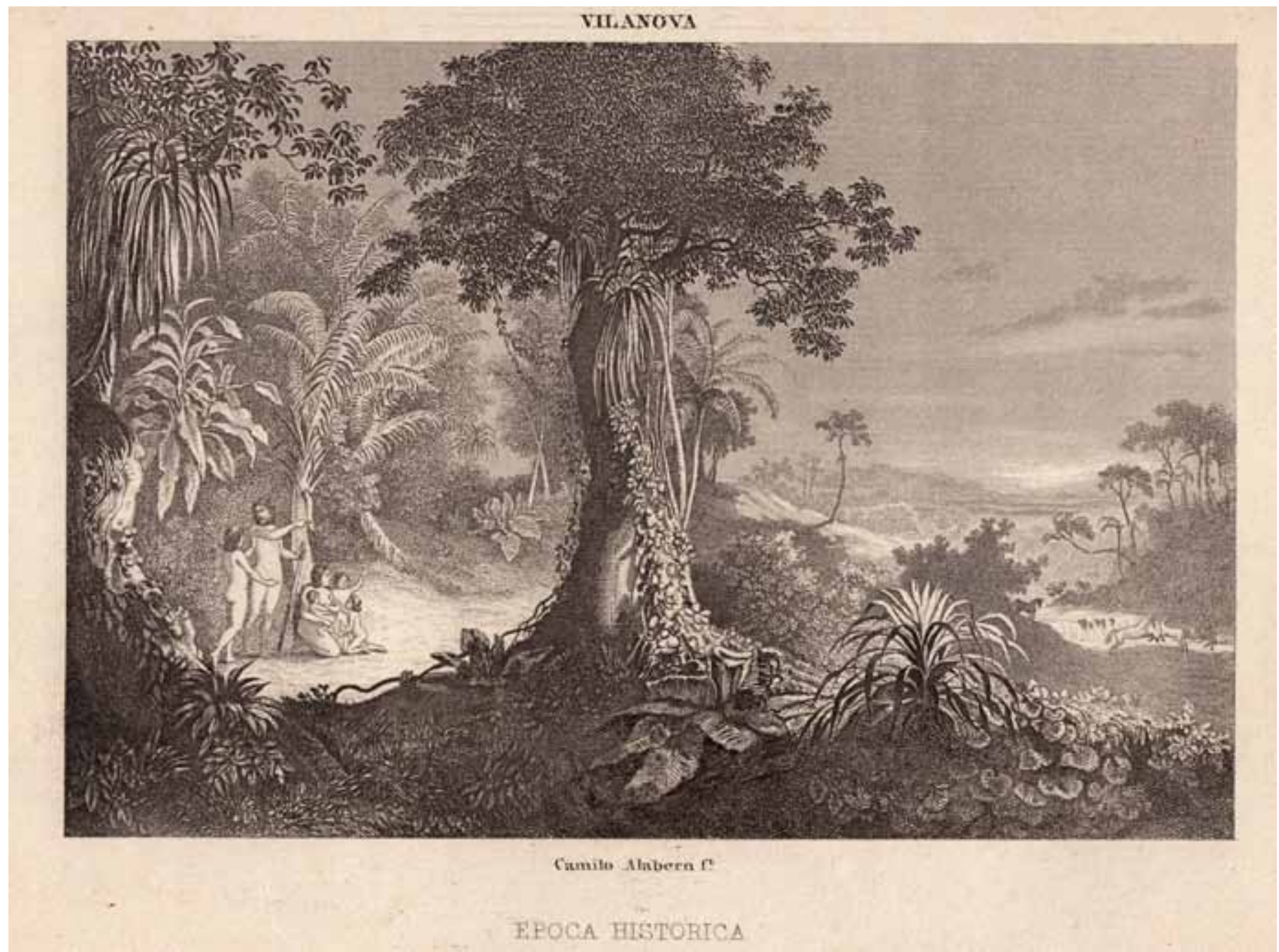

Figura 4. Primera reconstrucción de un paleoambiente en España del Pleistoceno, realizada por Vilanova y publicada en 1891. Obsérvese que frente a una flora muy antigua, el tipo humano es prácticamente como el actual. Vilanova defendía que el ser humano había sido creado con todas las potencialidades desde el primer momento (Vilanova and Rada, 1891).

Figure 4. First reconstruction of a Pleistocene paleoenvironment in Spain, conducted by Vilanova and published in 1891. Note that in front of an ancient flora, the human being is almost like the present day. Vilanova argued that man was created with all the potential since the Creation (Vilanova and Rada, 1891).

que tendrán un amplio reconocimiento no sólo en nuestro país, sino también en el resto de Europa llegando a publicar de manera asidua en revistas tan relevantes en ese momento como L'Anthropologie.

Con la Geología irrumpieron en la Arqueología la Estratigrafía y la Paleogeografía. De hecho, las discusiones sobre los estratos del valle del Manzanares en los que apareció la industria de San Isidro se mantuvieron presentes durante todo el siglo XIX. Al corte estratigráfico que incluía Vilanova en su obra Origen, Naturaleza y Antigüedad del Hombre (Fig. 5) (Vilanova, 1872), hay que destacar el que se publicó a finales del siglo XIX, pero con los datos de mediados de siglo, cuando aparecieron los restos de Elephas que exhumaron Graells (1809-1898) y Prado (Graells, 1899) (Fig. 6), y el que elaboraría Siret también a finales de siglo (Siret, 2001) (publicación con maravillosos dibujos y escrita y galardonada con el premio Martorell en 1891, pero que no ha sido publicada hasta 2001).

Un descubrimiento de gran importancia a finales del s. XIX fue el de la "mandíbula de Bañolas" en 1887, primer resto humano del paleolítico encontrado en España y uno de los primeros de Europa. Descubierta de manera fortuita por un maestro cantero, Pere Alsius (1839-1915) se dio cuenta de su gran antigüedad, en parte gracias a su contexto geológico (Ayarzagüena, 1989: 436). Alsius, farmacéutico de 


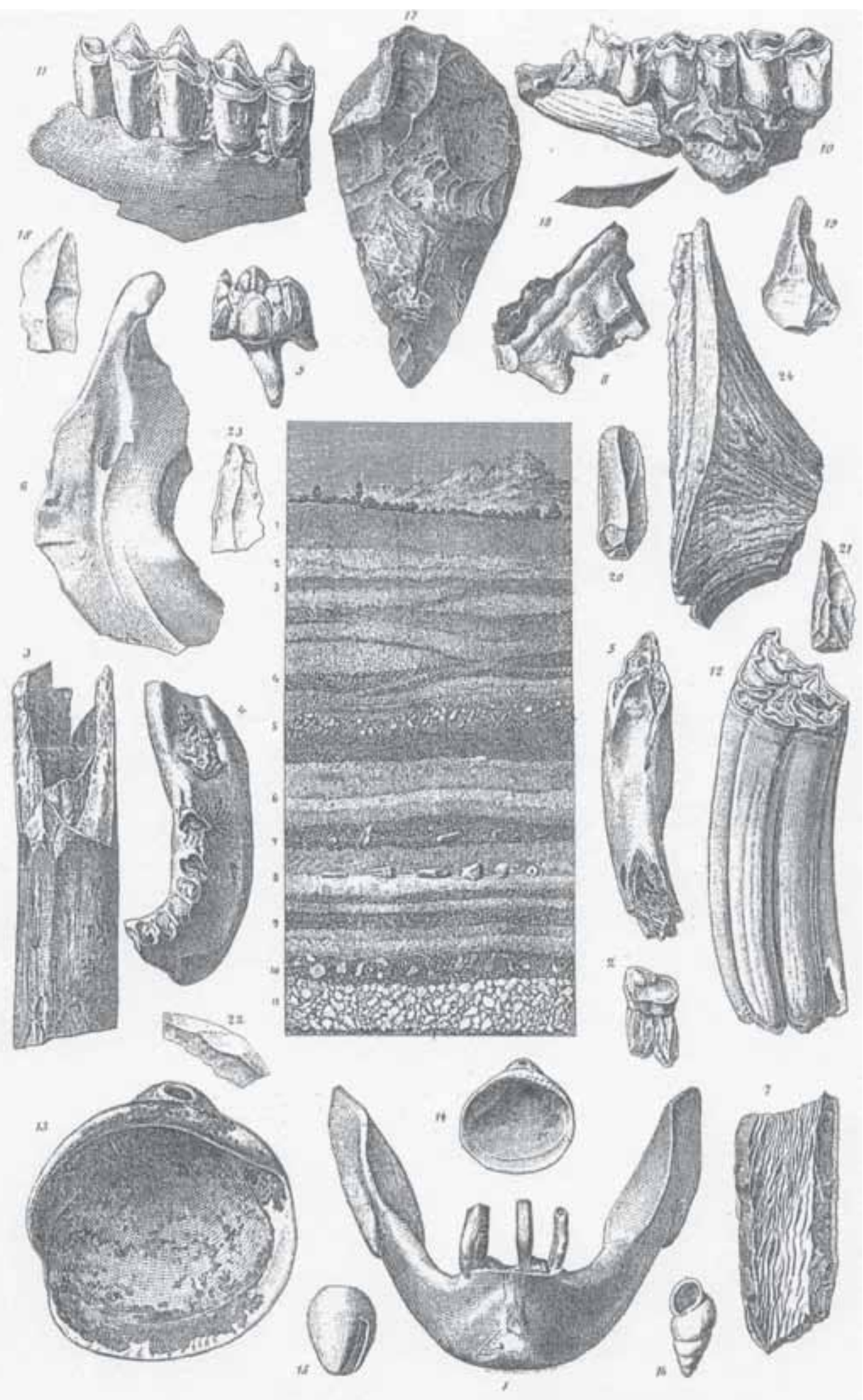

Figura 5. Lámina publicada por Vilanova en 1872, donde se observa el conocido como Corte Rotondo (Vilanova, 1872). Figure 5. Sheet published by Vilanova in 1872, where the section called Rotondo is observed (Vilanova, 1872). 


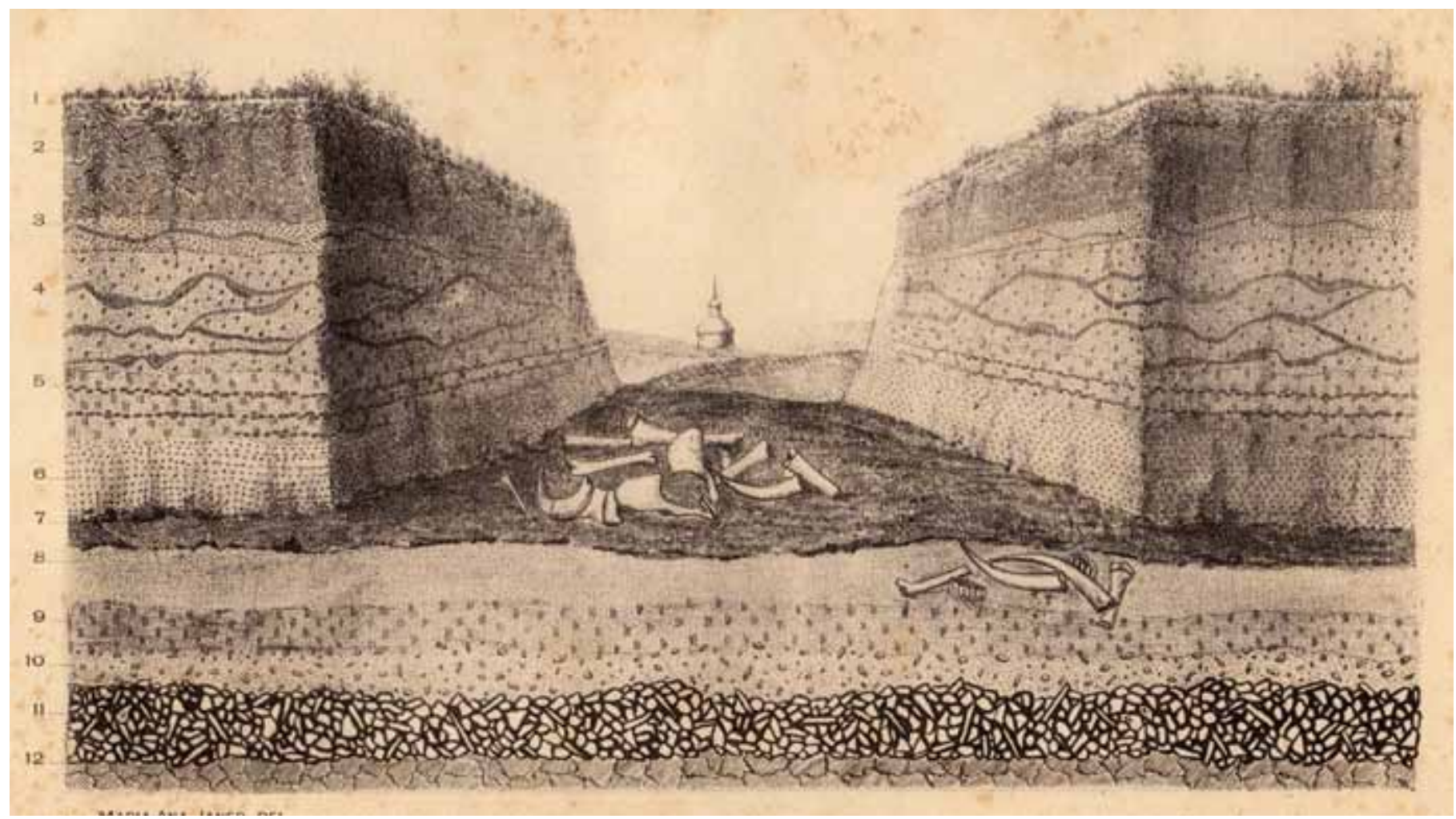

Figura 6. Lámina que representa el corte de San Isidro, donde en el horizonte se ve la cúpula de la Ermita del santo. Publicada por Graells (1897) se contextualiza perfectamente el lugar en el que aparecieron los restos de Elephas.

Figure 6. Sheet depicting San Isidro, where the dome of the chapel of the saint is on the horizon. Published by Graells (1897), the context in which the remains of Elephas were found is perfectly contextualized.

profesión, pudo darse cuenta de la antigüedad de la pieza toda vez que él ya había realizado previamente una estudio geológico de la cuenca de Bañolas (Alsius, 1871). Podemos darnos cuenta de lo que este hallazgo supuso toda vez que aunque se encontraba industria del Paleolítico, no se encontraban los restos de aquellos seres humanos que la habían realizado, lo que implicaba que aquellos que combatían a la Prehistoria encontraban un argumento sólido en la falta de hallazgos de estos restos. Así pues, la mandíbula de Bañolas, bien contextualizada geológicamente, supuso un impulso para los estudios prehistóricos en España.

\section{La Arqueología prehistórica española en el primer cuarto del siglo $\mathrm{XX}$}

Tras la muerte de Vilanova en 1893 se producirá un parón en los estudios prehistóricos en España que durará unos veinte años y que coincide con el estancamiento que la ciencia en general tuvo a finales del siglo XIX. Asimismo, con los inicios de siglo la labor individual que había sido característica de la
Prehistoria en el siglo XIX, va a ser sustituida por una actuación más profesional y planificada a cargo de instituciones públicas o privadas (Moure, 2006:79). En el marco del yacimiento prehistórico que había sido estrella durante el siglo XIX en España, San Isidro y sus alrededores, las investigaciones prehistóricas prácticamente desaparecieron, y la iniciativa más importante en este sentido fue la creación del Museo Protohistórico lbérico el 11 de abril de 1897 en el local de las madrileñas Escuelas Aguirre, con las colecciones de Emilio Rotondo Nicoláu (1849-1916) (Ayarzagüena, 2002:44).

Aun así, a principios de siglo tenemos las excavaciones del Marques de Cerralbo (1845-1922) en Torralba (entre 1909 y 1913) y Ambrona (entre 1914 y 1916), que en muchos aspectos podrían catalogarse como de carácter decimonónico, pero que fueron las dos primeras excavaciones de Paleolítico inferior que se realizaron en España en el siglo XX (Santonja, Pérez González y Flores, 2005).

Las repercusiones de la muerte de Vilanova coincidieron con la crisis del 98, y una situación agónica de la ciencia en general, que se contraponía con las ansias de regeneracionismo que venían ya larvadas 
Ayarzagüena Sanz, M., 2018. El papel desempeñado por geólogos e ingenieros de... Boletín Geológico y Minero, 129 (1/2): 13-33

desde el Sexenio Revolucionario (1868-1874). Todo ello se materializó en diversas iniciativas. Por una parte, en 1900 se crea el Ministerio de Instrucción Pública y Bellas Artes, que incluía a la Dirección General de Bellas Artes, encargada de tutelar aquellos temas relacionados con el patrimonio histórico artístico. Asimismo, se crea la Junta para Ampliación de Estudios e Investigaciones Científicas (JAE), por RD del 11 de enero de 1907 bajo el control intelectual e ideológico de miembros de la Institución Libre de Enseñanza, en la que tuvo un papel relevante Eduardo Hernández-Pacheco (1872-1965). La JAE ayudó a poner en pie un programa de reconstitución y europeización de España a través de una política de pensiones en el extranjero y de la creación de los instrumentos científicos y educativos necesarios para que esos conocimientos adquiridos en el extranjero pudieran llegar a la sociedad española (López-Ocón, 2010:164).

En 1911 se promulga la Ley General de Excavaciones, primera ley de excavaciones publicada en España, y cuyo objetivo principal era frenar el expolio al que se veían sometidos los yacimientos españoles de mayor renombre, por ejemplo las coronas de Guarrazar, que habían salido para Francia a mediados del siglo XIX, o la Dama de Elche, con el mismo destino y ya a finales del siglo XIX. También a finales del siglo XIX y principios del XX saldrán fuera de nuestras fronteras parte de las colecciones de los hermanos Siret, así como buena parte de los bronces ibéricos de El Collado de los Jardines (Santa Elena, Jaén).

En 1912 se crea la Junta Superior de Excavaciones y Antigüedades, organismo encargado de hacer cumplir la Ley General de Excavaciones. La Junta para la Ampliación de Estudios retomó la tradición de formación en el extranjero, como ya se hubiera hecho en los siglos anteriores, con Antonio Gimbernat (17341816) en el siglo XVIII y Juan Vilanova en el siglo XIX. Uno de ellos sería Eduardo Hernández Pacheco, que en 1910 ganó la cátedra de Geología de la Universidad de Madrid, cargo que llevaba aparejado la de Jefe de Sección de Geología y Paleontología estratigráfica del Museo de Ciencias Naturales. La Junta para la Ampliación de Estudios creó el Centro de Estudios Históricos, por R.D. de 18 de marzo de 1910. A él pertenecieron Ramón Menéndez Pidal (1869-1968) (en la sección de Filología) y Eduardo Hinojosa (1852-1919), Rafael Altamira (1866-1951), Américo Castro (1885-1972) y Pedro Bosch Gimpera (1891-1974), como más destacados. Objeto de estudio de este centro era todo aquello que pudiera aportar conocimiento histórico $\mathrm{y}$, muy especialmente, la Arqueología. Se promovió entonces una sección de
Arqueología que inició sus trabajos en 1914, coordinada por Manuel Gómez Moreno (1870-1970) y a la que pertenecieron también Juan Cabré (1882-1947), Cayetano de Mergelina (1890-1962) y Diego Angulo (1901-1986).

La Comisión de Investigaciones Paleontológicas y Prehistóricas se crea en 1912, también en el seno de la Junta para Ampliación de Estudios. Eduardo Hernández Pacheco coincide en una estancia en París con Enrique de Aguilera y Gamboa, Marqués de Cerralbo, donde acuerdan crear una institución española que controlara las investigaciones prehistóricas que se hicieran en nuestro país, centrándose en el periodo Cuaternario. Cerralbo pasaría a ser el primer director de esa institución y Hernández-Pacheco, el Jefe de Trabajos y Director de Publicaciones (Rasilla, 1997: 433). Asimismo sería su director a partir de 1922, tras la muerte del Marqués de Cerralbo. Otros destacados miembros de la comisión serían Juan Cabré, comisario de exploraciones, y los colaboradores Ricardo Duque de Estrada, Conde de la Vega del Sella (1870-1941), Hugo Obermaier (1877-1946), Paul Wernert (1889-1972), Pedro Bosch Gimpera (18911974), Orestes Cendrero (1887-1946), Ismael del Pan (1889-1968) y Francisco Benítez Mellado (1883-1962). La sede de la Comisión se estableció en el Museo de Ciencias Naturales, si bien los trabajos, aunque abarcaron toda la península Ibérica, se localizaron en su mayoría en Asturias. Los trabajos de la Comisión se centraron preferentemente en el Paleolítico, siendo sus investigadores mayoritariamente geólogos $y$ otros naturalistas (Rasilla, 1997:434).

La razón ideológica por la que se creaba esta comisión se encuentra en lo más profundo del Regeneracionismo. Tras la muerte de Vilanova, los estudios prehistóricos habían quedado representados por Luis Siret (belga de nacimiento) y poco más. Con el cambio de siglo había venido a España Emile Cartailhac (1845-1921) a visitar la cueva de Altamira, publicando su Mea culpa de un sceptique (Cartailhac, 1902). Este reconocimiento del valor de las pinturas promoverá una lucha entre los investigadores franceses y españoles por ver quién iba a estudiar la cueva en un primer momento, y una latente lucha en décadas posteriores por la investigación de las cuevas cántabras. De una parte estaba Hermilio Alcalde del Río (1866-1947) y de la otra Henri Breuil (1877-1961). El Municipio de Santillana del Mar no quería que Breuil excavase la cueva por el temor a que los materiales salieran de España (Madariaga de la Campa, 1972: 35) (en la mente de todos estaba el caso de la Dama de Elche). Al final intermedió Hoyos Sainz para que trabajasen juntos Alcalde del Río y Breuil (Madariaga de la Campa, 1972: 36). Este trabajo de 
colaboración entre diversos grupos facilitará que en esa primera década del siglo $X X$ se produzca toda una cascada de descubrimientos en las cuevas cántabras, como El Castillo (Puente Viesgo) y Covalanas y La Haza (Ramales) debidas, sobre todo, en este caso, a la actividad prospectora de Alcalde del Río y del padre Lorenzo Sierra (1872-1947).

Al mismo tiempo, en 1906, el francés Henri Breuil y el alemán Hugo Obermaier (1877-1946) (que era discípulo de Breuil y seguidor de la corriente difusionista de la Escuela histórico-cultural de Viena) contactaron con el Príncipe Alberto I de Mónaco durante el XIII Congreso Internacional de Antropología y Arqueología Prehistórica celebrado en Mónaco y que se celebró bajo el patronazgo del Príncipe Alberto, quien solicitó a Breuil y Obermaier que le enseñaran diversas cuevas cantábricas con restos prehistóricos.
A partir de ahí se va a iniciar un patrocinio de las investigaciones de Breuil en España, publicándole la monografía sobre Altamira (Cartailhac y Breuil, 1906). Asimismo firmará dos contratos con Alcalde del Río por los que le financiaba las excavaciones de EI Castillo y otras cavernas de Cantabria a Alcalde del Río y a Sierra (1872-1947) en 1906 y 1909, pero comprometiéndose a que los materiales encontrados quedasen depositados en Santander.Y en 1911 verá la luz la obra Les Cavernes de la Région Cantabrique.

En 1910 el Príncipe de Mónaco funda el Institut de Paléontologie Humaine en París (IPH). Allí Henri Breuil será designado para dirigir la cátedra de Etnografía Prehistórica y Hugo Obermaier la de Geología del Cuaternario. Será entre 1910 y 1914 cuando el instituto centre sus investigaciones en las excavaciones de la cueva de El Castillo y lleguen a

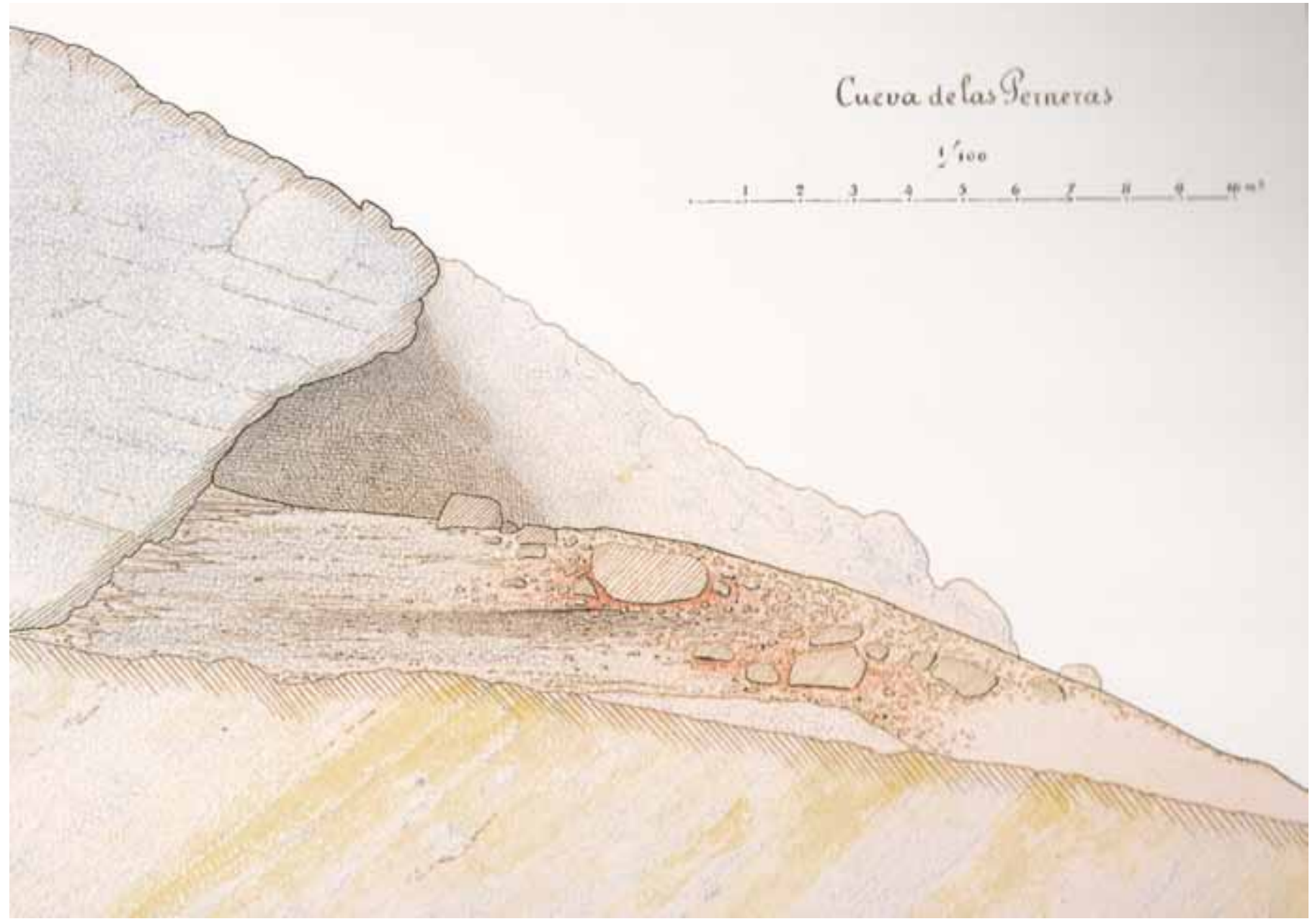

Figura 7. Lámina presentada por Luis Siret al Premio Martorell de 1891, pero que no ha sido publicada hasta el 2001. Siret explicaba las causas geológicas de la destrucción de la entrada de la cueva, de Las Perneras, así como su industria (Siret, 2001).

Figure 7. One of the plates presented by Luis Siret at Martorell Prize in 1891, but it was not published until 2001. Siret explained the geological causes of the destruction of the entrance of the cave Las Perneras and its industry (Siret, 2001). 
ella investigadores de talla internacional, como Teilhard de Chardin (1881-1955), Paul Wernert (18891972) o Ferdinand Birkner (1868-1944). También se promovería la formación de arqueólogos autóctonos que jugarían un importante papel, de la talla del Conde de la Vega del Sella (1870-1941), quien siempre relacionó la Geografía y la Geología con los hallazgos prehistóricos (Fig. 8).

Con el estallido de la I Guerra Mundial se pondrá fin a las actividades del Instituto de Paleontología Humana en la región cantábrica. Obermaier queda entonces sin financiación económica en España, encontrando en el padre Jesús Carballo (1874-1961), primero, y en el Conde de la Vega del Sella, después,

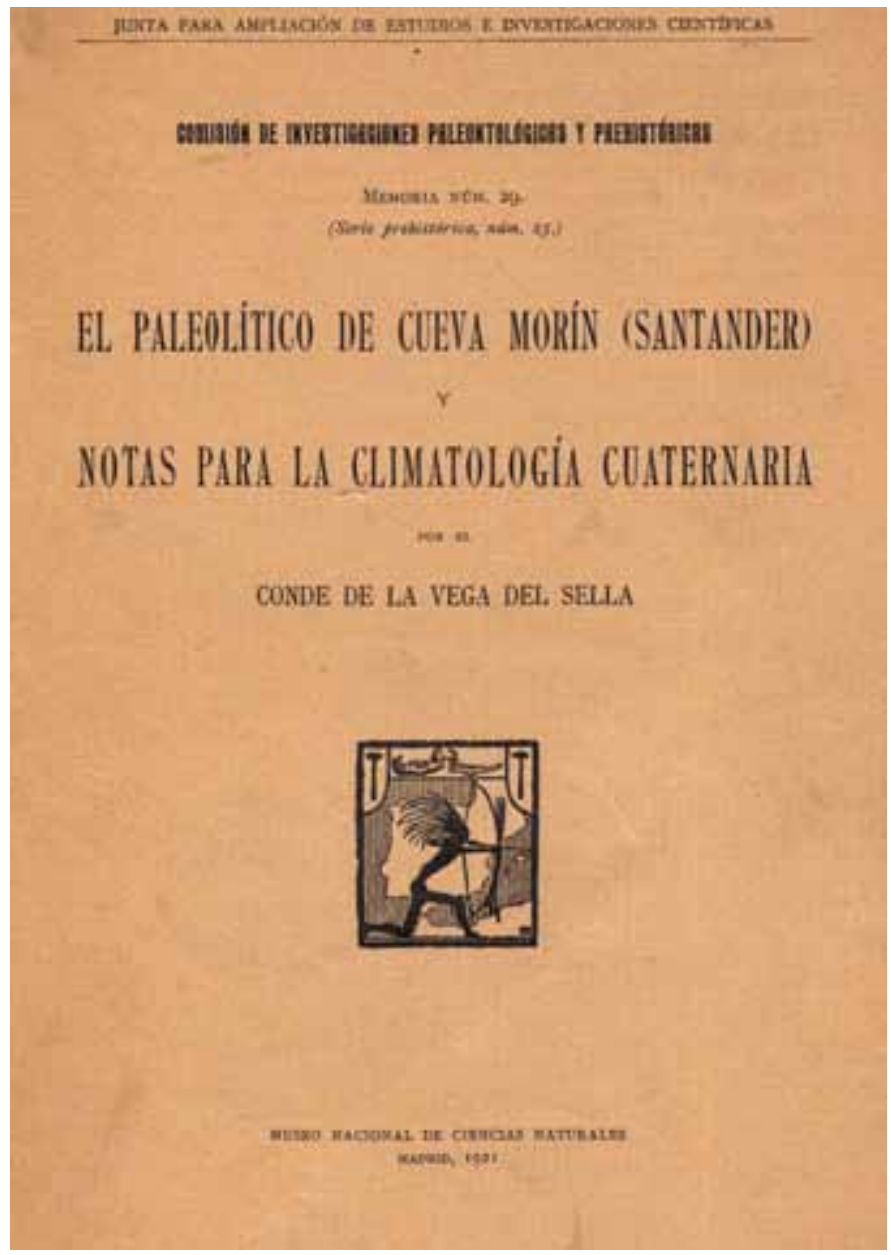

Figura 8. La obra del Conde de la Vega del Sella, El Paleolítico de Cueva Morín y notas para la Climatología cuaternaria, es en muchos aspectos una obra adelantada a su tiempo, pues no sólo estudia los niveles, sino que, además, trata de explicar geológicamente cómo se han formado los niveles.

Figure 8. The work of Count de la Vega del Sella, El Paleolítico de Cueva Morín y notas para la Climatología cuaternaria, is in many ways a work ahead of its time, not only for level of study, but also for the geological explanation about how the levels were formed. el apoyo necesario para poder sobrevivir en nuestro país. Eduardo Hernández Pacheco y el Conde de la Vega del Sella estaban prospectando en ese momento en la cueva de La Paloma (Soto de las Regueras, Asturias) cuando el conde puso en contacto a Eduardo Hernández Pacheco con Obermaier, quien le propuso para que formara parte de la Comisión de Investigaciones Paleontológicas y Prehistóricas (Fig. 9). Dentro de la Comisión su aportación más importante fue su obra El hombre fósil (Fig. 10). Esta publicación hacía el número 9 de la Comisión y tuvo dos ediciones, una en 1916 y otra en 1925, la cual actualizaba en buena medida la de 1916. Los descubrimientos desde 1916 habían sido de tal magnitud que en la segunda edición Obermaier afirmaba: "Los multiplicados descubrimientos y las muchas publicaciones que han surgido sin interrupción desde 1915 me han obligado a completar cada capítulo con importantes adiciones, y el resultado ha sido la refundición casi total de la obra" (Obermaier, 1925: IX). Para darnos cuenta de la importancia que Obermaier daba a la Geología basta con fijarnos en el índice. El primer capítulo estaba dedicado a "El Hombre Terciario y los eolitos" (tema de actualidad en ese momento), y el segundo capítulo trataba de "Era Cuaternaria:

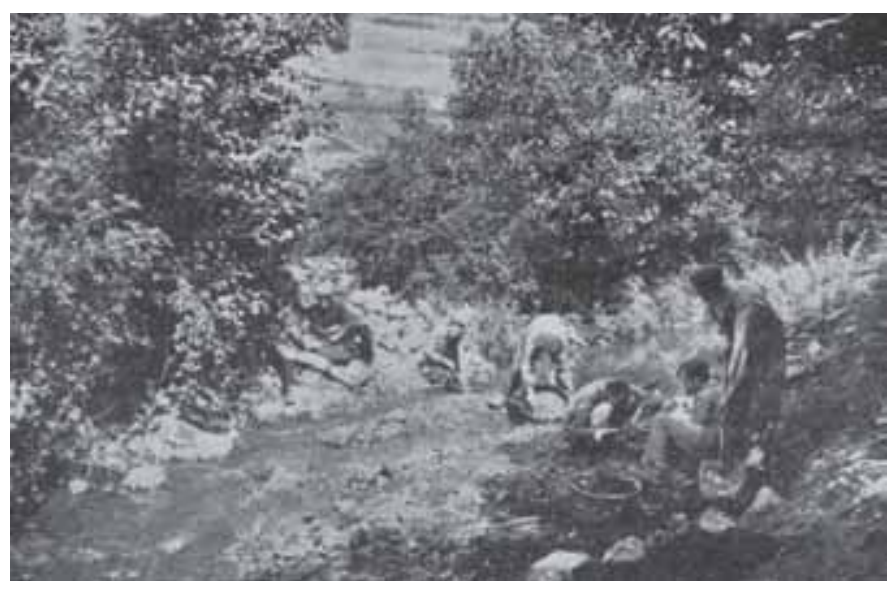

Figura 9. En esta foto se observa muy bien parte del método de trabajo arqueológico en el primer tercio del siglo $X X$. La foto se corresponde con las operaciones de lavado, cribado y escogido de materiales procedentes de la cueva de la Paloma (HernándezPacheco, 1959: 320). Los cestos de tierra se bajaban al riachuelo próximo, donde se hacía pasar el agua por la criba conteniendo la tierra. Posteriormente se escogían los materiales que se creían de interés, desechándose el resto.

Figure 9. In this photo we can see the method for archaeological work in the first third of the twentieth century. The photo corresponds to the washing, screening and choice of materials from the Cave de la Paloma (Hernandez-Pacheco, 1959: 320). The baskets of earth were carried down to the next stream, where the water passed through the sieve containing the soil. Subsequently the interesting objects were selected, discarding the rest. 


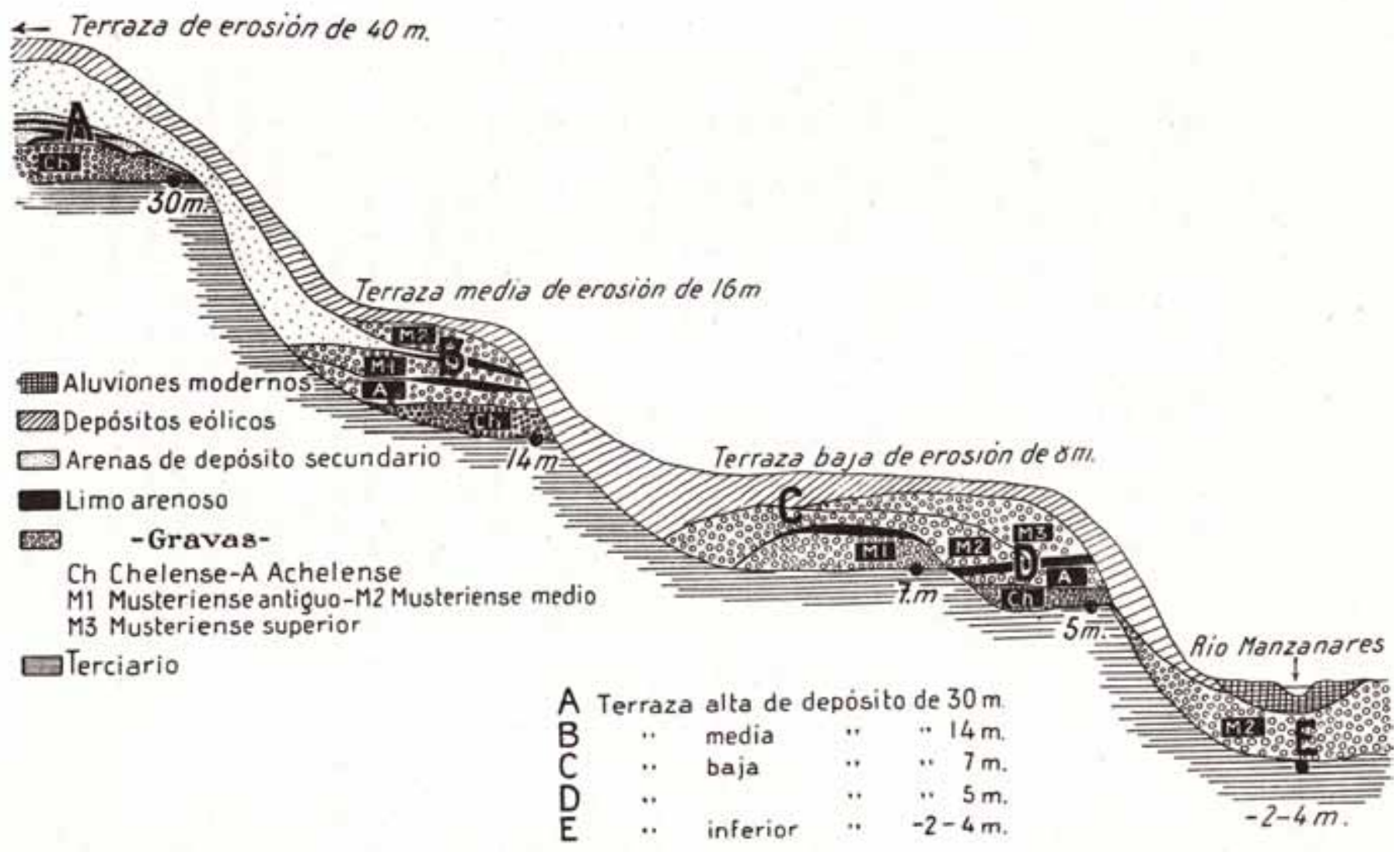

Figura 10. Obermaier, en su obra El Hombre Fósil (1925), planteaba la estratigrafía del yacimiento de San Isidro. Desde el siglo XIX fueron muchos los que llevaron a cabo dicho intento: Vilanova, Barón de Baye, Siret, etc... Si bien, nunca fue admitida sin discusión. Esta, presentada por Obermaier, es una de las realizadas con mejor criterio.

Figure 10. Obermaier, in his book El Hombre Fósil (1925), raised the stratigraphy of San Isidro. Since the nineteenth century there were many who carried out such an attempt: Vilanova, Baron de Baye, Siret, etc... None of them was admitted without any discussion. This, by Obermaier, is one of those made with better judgment.

Geología" (mostrando todo lo que en ese momento se sabía sobre glaciarismo).

En cuanto a los principales resultados obtenidos en España por la labor del IPH y de la Comisión, Hernández Pacheco diferencia dos tipos de investigaciones (Hernández Pacheco, 1956: 41): “Uno, (...) (donde se trataban) los problemas de orden geológico o paleontológico, relacionados con el general prehistórico. Otro tipo de investigaciones fueron concretamente de índole arqueológica (estudio de yacimientos y de pinturas rupestres". Se estudiaron las terrazas fluviales hispanas, los movimientos del litoral en el Cuaternario, el glaciarismo cuaternario, restos de carácter paleontológico de grandes mamíferos, restos paleontológicos asociados a industria lítica, la climatología en el Paleolítico superior, antropometría de restos humanos fósiles, etc. Lo indicativo de la personalidad de estos investigadores del primer tercio del siglo $X X$, es que habitualmente realizaban de manera indistinta los dos tipos de investigaciones: los de carácter más estrictamente geológico, así como los de naturaleza arqueológica.

Al tiempo que se crean instituciones de carácter estatal como las ya mencionadas, otras se establecerán en las zonas periféricas, como en Cataluña, donde con financiación de las diputaciones catalanas se funda el Institut d'Estudis Catalans en 1907. En 1911, dentro de este Institut se crea la Sección HistóricoArqueológica, y en 1915 se designa a Pere Bosch Gimpera como director de excavaciones del Institut y profesor de los Estudios Universitarios Catalanes. Creará, junto con otros, la Associació Catalana d'Antropologia, Etnografia i Prehistòria en 1923 bajo la presidencia de Telesforo de Aranzadi (1860-1945) con el fin de agrupar las actividades que estaban desarrollándose por parte del Laboratorio de Antropología, el Archivo de Etnografía y Folklore y el Seminario de Prehistoria.

Bosch, tras regresar de Alemania y obtener la cátedra en Historia Antigua y Medieval iniciará sus clases 
en el curso de 1915-1916. En este primer año tendrá como alumno, ente otros, a Lluis Pericot i García (1899-1978). En el curso siguiente, organizará, según el modelo alemán un Seminario de Prehistoria, de donde saldrán varios de los prehistoriadores más importantes del primer tercio del siglo: Alberto del Castillo, Elies Serra Ràfols y su hermano Josep de Calasanç (1900-1971). Toda vez que el Seminari, como tal, carecía de reconocimiento académico oficial (Quesada, 2005: 180) y el hecho de que Bosch fuera catedrático universitario y a su vez dirigiese esta institución, motivó que poco a poco el Seminari adquiriese rango propio y se convirtiese en auténtico centro de investigación. Bosch y estos últimos, junto con Josep Colominas i Roca (1883-1958), establecieron "el primer gran sistema coherente de prehistoria peninsular que, durante dos décadas, constituyó la ortodoxia, para la Prehistoria española" (Cortadella, 2003: LXXXVI-LXXXVII), y cuyo modelo de seminario se exportó a otras regiones de España, como País Vasco, Valencia o Madrid (Quesada, 2005: 180). A pesar de ello, dada la dispersión de varios de sus miembros tras la consecución de cátedras fuera de Cataluña, algunos historiógrafos entienden que dejó, como escuela, un bagaje demasiado exiguo como para poder decir que se vertebrara una escuela efectiva (Gracia, 2011:182). Los trabajos de Manuel Cazurro (1865-1935) también resultaron de gran utilidad, especialmente en El Cuaternario y las estaciones de la época Paleolítica en Cataluña (Cazurro, 1919), donde resumía todos los datos existentes hasta el momento, y que incluyendo los datos geológicos y paleontológicos, los ponía en relación con todos los yacimientos conocidos en Cataluña con industrias paleolíticas (Genera, 2005: 198).

En Euskadi destacará en el primer tercio de siglo el grupo formado por José Miguel de Barandiarán (1889-1991), Enrique de Eguren (1888-1941) y Telesforo de Aranzadi. El equipo se formó en 1916 (Altuna, 1990: 12). Barandiarán se puso en contacto con Aranzadi y éste le animó para que también contactara con Eguren, entonces catedrático de Geología de la Universidad de Oviedo. Los tres tenían un marcado perfil como prehistoriadores, si bien Barandiarán era más etnógrafo, mientras que Aranzadi era más antropólogo y Eguren eran de un perfil más naturalista. Dispersado el grupo durante la Guerra Civil, de alguna manera se podría considerar que este grupo será el germen ideológico de lo que luego será la Sociedad de Ciencias Naturales Aranzadi, fundada en 1947, cuando ya del trío sólo sobrevivía José Miguel de Barandiarán, quien fue el referente de la sociedad durante varias décadas.

En la región valenciana, tras el siglo XIX, en la que sobre todo gracias a la labor de Juan Vilanova, se prospectaron un buen número de yacimientos prehistóricos, con el cambio de siglo la investigación prehistórica estaba prácticamente desaparecida. Y no será hasta la tercera década del siglo, en 1927, cuando en Valencia se cree el Servicio de Investigación Prehistórica, con las secciones de excavaciones, laboratorio y biblioteca especializada, museo y publicaciones (Anónimo, 1929). Desde el principio, el SIP y el Museo fueron dirigidos por Isidro Ballester i Tormo (1876-1950), contando con Lluis Pericot como subdirector del servicio (no puede ser casualidad que coincida la creación del SIP con la llegada de Pericot a Valencia como profesor de su universidad, también en 1927). Otros colaboradores fueron Fernando Ponsell Cortés (1898-1975), Mariano Jornet Perales (1869-1953) y Gonzalo Viñes (1883-1936). Además, Emilio Gandía Ortega (1866-1939) fue nombrado conservador honorario de su Museo de Prehistoria. Para que nos hagamos idea de la actividad del servicio, sólo mencionar que durante 1929 se excavaron por el SIP, ente otros, la Cova del Parpalló (Gandía), Cova del Llop (Gandía), Altet de Fontanares (Játiva) y La Bastida de Les Alcuses (Mogente).

En la otra punta de la geografía española, en Galicia, en 1923 se crea el Seminario de Estudos Galegos. El iniciador fue Antón Losada Diéguez (18841929), que en su casa de Pontevedra creó la Xuntanza de Estudos e Investigacións Históricas e Arqueolóxicas. Paralelamente, Wenceslao Requejo Buet proponía formar un grupo que se interesase primordialmente por los problemas de la cultura, el arte, la literatura y la historia. Sus objetivos principales eran el estudio y divulgación del patrimonio cultural gallego y la formación de investigadores. En la reunión en la que se constituyó, celebrada el 12 de octubre de 1923 en Ortoño, se recogía la tradición intelectual de la Junta para la Ampliación de Estudios con un planteamiento galleguista. Desde el historicismo, por medio del estudio de la Historia y de la Prehistoria, se intentaban aportar hipótesis científicas que cimentasen el nacionalismo gallego (Prado, 1997: 458-459). Estaba organizada en doce secciones, siendo una de ellas la de Prehistoria, de la cual era su coordinador Florentino López Cuevillas. Formó entonces equipo con Fermín Bouza Brey, excavando el castro de O Neixón en 1925, y en 1927 realizaron el primer viaje arqueológico a través de toda la geografía gallega. En el año de 1929 Cuevillas, junto con Pericot, excavaron el castro de Troña. Los estudios sobre el Paleolítico en un principio no tuvieron mucho peso, si bien la idea de la existencia de un Preasturiense luso-galaico y sus relaciones atlánticas, servían muy bien a los planteamientos ideológicos de 
los miembros del movimiento. Es digno de hacer notar que la creación del Seminario coincide en el tiempo (es un mes más tarde) con el golpe de estado de Primo de Rivera, con un carácter centralista, militar y antidemocrático, lo que de alguna manera es una respuesta defensiva casi inmediata a lo que estaba sucediendo en Madrid.

Un cambio significativo para los estudios prehistóricos españoles fue la creación en 1922 de la Cátedra de Historia Primitiva del Hombre expresamente para Obermaier, quien ingresó, además, en la Real Academia de la Historia en 1925, con ceremonia de ingreso en 1926 y contestación de Antonio Ballesteros. La creación de la cátedra no estuvo exenta de problemas (Mederos, 2010-2011), pues tras la I Guerra Mundial, Obermaier había quedado refugiado en España. En Francia estaba mal considerado por ser de origen alemán, y en Alemania no era aceptado por francófilo. A todo ello hubo que sumar que, enfrentado a Hernández Pacheco, éste promovió su cese de la Comisión en 1919. Esta circunstancia se aprovechó para integrarlo en las estructuras científicas españolas de pleno derecho, concediéndole, además, la nacionalidad española. Obermaier gozaba del apoyo del Duque de Alba, del que era su capellán personal, y de la reina Victoria Eugenia, esposa de Alfonso XIII, siéndole concedida una cátedra de Historia Primitiva del Hombre en la Facultad de Filosofía y Letras. Lo cierto es que ya existía una cátedra de Antropología en la Facultad de Ciencias que impartía, entre otras materias, ciencia prehistórica y que fue inaugurada por Manuel Antón y Ferrándiz, y en cuya oposición intervino Vilanova. Antón, jubilado en 1919, había sido sustituido en la cátedra por Francisco de las Barras de Aragón. Por otra parte el Decano de Ciencias, Rodríguez Carracido, planteaba su queja al retirarse estos estudios de la Facultad de Ciencias argumentando "la prehistoria, circunscribiéndose a hechos paleontológicos, geológicos y etnográficos es propia de las ciencias naturales" (Mederos, 20102011: 247).

\section{Los años previos a la II República española}

La fuerza que estaban tomando las estructuras científicas creadas en España en las dos primeras décadas del siglo $X X Y$, muy especialmente, las de la Junta para la Ampliación de Estudios, se dejaron notar en todos los ámbitos de la ciencia española; y también en los estudios prehistóricos. Una muestra de ello la tenemos en el XIV Congreso Geológico Internacional, que había sido confiado en 1922 a los geólogos españoles y que se desarrolló en Madrid en el año de
1926. Aprovechando tal evento se inauguró el actual edificio del Instituto Geológico y Minero de España en la calle Ríos Rosas de Madrid. En el congreso participó Eduardo Hernández-Pacheco como vicepresidente $y$, dentro de la delegación española se encontraban, entre otros científicos de reconocido prestigio por sus estudios prehistóricos, José Royo y Gómez (18951961) en representación de la Asociación Española para el Progreso de las Ciencias, José Pérez de Barradas (1897-1981), en representación del Ayuntamiento de Madrid, Antonio Carbonell y TrilloFigueroa (1885-1947), en representación de la Cámara Minera de Córdoba, de la Jefatura de Minas de Córdoba y de la Real Academia de Ciencias de Córdoba, Ricardo Duque de Estrada, Conde de la Vega del Sella (1870-1941), en representación de la Junta para la Ampliación de Estudios, etc. Muy probablemente por intercesión de Obermaier, Pérez de Barradas tuvo el encargo del Ayuntamiento de Madrid de ordenar y acrecentar las colecciones arqueológicas existentes, para lo cual debía realizar un estudio geológico del valle del Manzanares, preparar una memoria y una pequeña exposición de contenido geológico y prehistórico (Carrera Hontana y Martín Flores, 1997: 582).

Cuando ya parecían finalizar las funciones de Pérez de Barradas en el Ayuntamiento de Madrid, un nuevo encargo hizo que no se desvinculase del mismo. Estaba previsto que al año siguiente, en 1927, tuviese lugar en Madrid el XV Congreso Internacional de Antropología y Arqueología Prehistóricas, para lo que el Ayuntamiento de Madrid le encargó su organización. Y aunque el congreso acabó realizándose en Portugal por causas aún no muy claras, al menos quedó la sensibilización del Ayuntamiento del Madrid hacia los estudios prehistóricos. Así en 1929 se crea el Servicio de Investigaciones Prehistóricas de titularidad municipal (Martín Flores, 2001: 11). Podríamos decir que de alguna manera se formó un grupo y, con este, se institucionalizó la Prehistoria en Madrid. Tras los trabajos de Casiano de Prado y Juan Vilanova a lo largo del siglo XIX poco se había hecho en cuanto a la investigación de los yacimientos del valle del Manzanares. Y lo que es peor. El valle del Manzanares era uno de los yacimientos paleolíticos más importantes del mundo y el crecimiento de Madrid iba acabando con todo el registro arqueológico existente. A partir de 1918, Pérez de Barradas una veces sólo, otras veces con Paul Wernert o con Hugo Obermaier, realizó un estudio exhaustivo de los yacimientos paleolíticos de los alrededores de Madrid, especialmente de los valles del Manzanares y del Jarama. Los fundamentos metodológicos de 
Pérez de Barradas eran, según las enseñanzas de Obermaier, el conocimiento geológico del terreno y el análisis estratigráfico, así como la tipología lítica (Martín Flores, 2001: 8).

Otra de las repercusiones del XV Congreso Internacional de Antropología y Arqueología Prehistóricas fue la creación de la Sociedad Española de Antropología, Etnografía y Prehistoria, en cuya primera directiva figuraban Eduardo Hernández Pacheco, como vocal segundo, Francisco de la Barras de Aragón, como tesorero, Luis de Hoyos Sáinz (18681951) como secretario y Juan Cabré como vicesecretario (Sánchez Gómez, 1990: 63-64). Esta sociedad tuvo un perfil más marcado hacia la Etnología que hacia la Prehistoria.

El Instituto Geológico y Minero continuó en las postrimerías del reinado de Alfonso XIII manteniendo cierto interés por los estudios prehistóricos. Además de las aportaciones puntuales que en el campo de la prehistoria hacían algunos de sus miembros, como Antonio Carbonell Trillo-Figueroa (vocal del Instituto desde 1920), en esos momentos el máximo exponente de la prehistoria cordobesa de los años 20. Pérez de Barradas, por su parte, publicó en el Boletín Geológico y Minero (Pérez de Barradas, 1929), la más importante síntesis que sobre los conocimientos existentes sobre la prehistoria madrileña había a finales de los años 20.

En 1929 tendrán lugar las exposiciones internacionales de Sevilla y Barcelona. La exposición Iberoamericana de Sevilla, si bien tuvo materiales de naturaleza arqueológica, no es de gran interés para la historiografía de la Prehistoria. De mayor interés para el contenido del presente texto fue la Exposición Internacional de Barcelona. Formando parte de la Exposición Internacional se encontraba otra sobre "EI arte en España", siendo los encargados de la sección "España primitiva" José Calassanç Serra i Ràfols (1902-1971) y Pedro Bosch Gimpera. En dicha exposición se reunieron todo tipo de documentos que permitieran hacerse cabal idea de cómo había sido el devenir de la sociedad española. En relación con la Prehistoria la exposición se iniciaba con objetos procedentes de los alrededores de Madrid, para posteriormente incluir reproducciones de pinturas rupestres, útiles de objetos del Paleolítico superior del levante español, reproducciones de restos humanos prehistóricos, como el cráneo de Gibraltar o la mandíbula de Bañolas, etc. (Berwick y Alba, 1931).

\section{La II República y la Guerra Civil}

Con el levantamiento popular tras las elecciones del 14 de abril de 1931, Alfonso XIII tiene que salir de España y se declara la II República. El apoyo que había dado a la dictadura de Miguel Primo de Rivera le pasó al monarca factura política $y$, un año después de tener que dimitir Primo de Rivera y exilarse, lo mismo tuvo que hacer Alfonso XIII. En una coyuntura de gran efervescencia política y sociedad muy polarizada, con una importante crisis económica que había llegado a Europa poco después del Crack del 29 y con fuerte descrédito de la monarquía, la república era la única salida viable. En cualquier caso, las estructuras culturales sufrieron poco en esos momentos. Y más al contrario, los gobiernos de la II República tuvieron especial interés en desarrollar a una España, que aún mantenía unas tasas de analfabetismo tercermundistas.

Nuevos aires de libertad, metodologías docentes más avanzadas y mayor optimismo en las clases medias, serán el norte de este nuevo momento en la Historia de España, donde en educación primaban los principios de la Institución Libre de Enseñanza. La Constitución Española de 1931 será una de las más avanzadas en la protección del Patrimonio Histórico, sobre todo en lo relativo a la amplitud de los bienes a proteger, dada la incorporación del valor cultural en la misma (Becerra, 2000: 14). Todo ello se plasmará en la Ley de Patrimonio Artístico de 1933, que provocará diversos cambios en la Junta Superior de Excavaciones y Antigüedades, que pasará a llamarse Junta del Tesoro Artístico.

Un viaje, el "Crucero Universitario Mediterráneo", realizado en 1933 fue un buen ejemplo de los nuevos aires que corrían en la ciencia en general, en la arqueología en particular y en la metodología docente (Gracia y Fullola, 2006). La idea era romper con las clases magistrales tradicionales mediante la docencia impartida a bordo del Ciudad de Cádiz. El viaje duró 48 días y participaron profesores de la talla intelectual de Antonio García y Bellido (1903-1972), Manuel Gómez Moreno, Julio Martínez Santa Olalla (19051972), Cayetano Mergelina Luna (1890-1962), Hugo Obermaier, Luis Pericot García, Blas Taracena Aguirre (1865-1951), Elías Tormo y Monzó (1869-1957) y Antonio Tovar Llorente (1911-1985). Y alumnos, algunos de los que liderarán la arqueología en el franquismo, como Martín Almagro Basch (1911-1984), Carlos Alonso del Real (1914-1993) o Felipa Niño Mas (1902-1992). También participarían intelectuales de la talla de Gregorio Marañón Moya (profesor) (18871960) y Guillermo Díaz Plaja (profesor) (1909-1984) o Julián Marías Aguilera (alumno) (1914-2005) y Fernando Chueca Goitia (estudiante) (1911-2004).

Los grupos que se habían formado durante el primer tercio del siglo $X X$, tomarán aún mayor fuerza en la II República. Se reorganizarán las distintas institu- 
ciones encargadas de la Arqueología prehistórica, como el SIP valenciano.

La creación, en 1933 de la Universidad Autónoma de Barcelona, propició el regreso de Pericot a Barcelona para ocupar la cátedra de Etnología, donde pudo colaborar con Bosch Gimpera. Bosch Gimpera fue detenido por su implicación, si bien de orden menor, en la sublevación de Lluis Companys del 6 de octubre de 1934 (Gracia, 2011:180). El Servei d'Investigacion Arquèologiques se integró, junto al Seminario de Prehistoria de la Universidad en el Museu d'Arqueología creado en 1935.

En Madrid prosiguió la labor del Servicio de Investigaciones Prehistóricas del Ayuntamiento de Madrid durante la República. El hecho más notable durante estos años fue la publicación del Anuario de Prehistoria Madrileña, donde quedó clara la intención de Servicio de expandir su ámbito de influencia más allá del término de la ciudad de Madrid.

A pesar de los avances realizados en cuanto a la metodología en Prehistoria, todavía la Estratigrafía no tenía la importancia debida al otorgarse muchas veces al interés por el estudio del objeto en sí mismo (Ruiz Zapatero, 1993: 47). La razón fundamental, en Prehistoria, se encontraba precisamente en un concepto tomado de la Paleontología, los "fósiles-guía". A partir de ahí, la Estratigrafía perderá mucho de su valor, al otorgarse a la "pieza-tipo" un valor fundamental (Hernández Pacheco, 1916), consideración que se mantendrá hasta bien entrado el siglo XX. Otra razón era que, en alguna medida, metodológicamente, aún no se había desvinculado para muchos la Arqueología de la Historia del Arte.

\section{La Geología y su relación con la Arqueología en el franquismo}

Tras la Guerra Civil, la Junta Superior de Excavaciones y Antigüedades fue sustituida por la Comisaría General de Excavaciones Arqueológicas, dirigida por Julio Martínez Santa-Olalla, persona de ideología filonazi. El fin de la Guerra Civil y la persecución de todos aquellos que habían tenido algún protagonismo, siquiera a nivel científico, con la República motivó que se pueda afirmar que durante el primer franquismo, a nivel científico, se produjo un desierto intelectual $y$, lógicamente, eso tuvo sus repercusiones en los estudios prehistóricos. Como afirman Santonja, Pérez González y Flores: “Después de 1936 el abandono de la investigación del Paleolítico en España fue prácticamente total, y sólo la reunión del algún congreso internacional, el IV de Ciencias Prehistóricas y Protohistóricas en 1954 y el V de Cuaternario (INQUA) en 1957, despertaría alguna atención hacia el Pleistoceno" (Santonja, Pérez González and Flores: 2005, 36).

A nivel organizativo en 1939 se creará el Consejo Superior de Investigaciones Científicas, que asumirá los recursos y parte de la estructura de la Junta para la Ampliación de Estudios e Investigaciones Científicas. Hasta finales de los años 50, como se ha expuesto en el párrafo anterior, no se dinamizan los estudios prehistóricos, y en 1958 se crea el Instituto Español de Prehistoria, dependiente del CSIC, que fue el primer organismo estatal consagrado totalmente a la investigación prehistórica (Vicent, 1993: 19). Martín Almagro Basch (1911-1984) será su primer director, que compatibilizará con la Cátedra de Historia Primitiva del Hombre de la Universidad Central de Madrid que había ganado en 1954. A partir de ahí Martín Almagro Basch tendrá un papel protagonista en la Prehistoria española hasta 1981, es decir, cuando ya había entrado la democracia en España.

Tras la Guerra Civil, junto con la depuración de muchos de los prehistoriadores que habían quedado en España (es el caso de Enrique Eguren y Bengoa (1898-1944) o de Francisco Jordá Cerdá (1914-2004)) se desmantelaron o transformaron todas las instituciones regionales que existían durante la República. La que era una boyante Escuela Catalana de Arqueología dirigida por Pedro Bosch Gimpera sufrió una práctica congelación tras el exilio de su dirigente (Díaz-Andreu, 1997: 548-549). El grupo vasco Aranzadi-Barandiarán-Eguren quedó disuelto: Aranzadi, retirado en Barcelona próximo a su jubilación, Barandiarán exilado en el País Vasco-Francés y Eguren, de rector en la Universidad de Oviedo, después de padecer dos procesos de depuración, y sufriendo el práctico desprecio de sus dos antiguos compañeros, que no querían ni escribirle. El grupo gallego del Seminario fue también duramente reprimido. Sus fondos expoliados e incorporados a la Universidad de Santiago de Compostela. Alguno de sus miembros fue asesinado (Ánxel Casal (18951936)), otros se exiliaron (Sebastián González GarcíaPaz o Luis Tobío) y otros tuvieron que pasar por procesos de depuración, como fue el caso de López Cuevillas (1886-1958). En el caso gallego se verificó una trasformación de instituciones para el nuevo régimen. Gracias a las gestiones de Xosé Filgueira Valverde (1906-1996) se fundó el Instituto de Estudios Gallegos "Padre Sarmiento", dependiente del Consejo Superior de Investigaciones Científicas.

En Cataluña, la obligada marcha de Bosch Gimpera al exilio por la persecución del régimen de Franco parecía que iba a dar al traste con la Escuela Catalana de Arqueología, si bien, aunque también 
Ayarzagüena Sanz, M., 2018. El papel desempeñado por geólogos e ingenieros de... Boletín Geológico y Minero, 129 (1/2): 13-33

Pericot sufrió un proceso de depuración, pudo continuar ocupando su cátedra, donde ejerció de maestro de Joan Maluquer de Motes (1915-1988), quien a su vez dirigió la tesis doctoral de Francisco Jordá Cerdá, la primera que sobre paleolítico se hizo en España. Otros discípulos de Pericot fueron Miquel Tarradell i Mateu (1920-1995), Eduard Ripoll i Perelló (19232006), Antonio Arribas Palau (1926-2002), etc. Esta escuela formada por Pericot dio como fruto a buena parte de los más importantes prehistoriadores de la segunda mitad del siglo XX. Con la victoria de Franco, Martín Almagro Basch fue nombrado director del Museo Arqueológico de Barcelona y del Servicio de Investigaciones Arqueológicas, pero que se centró durante 20 años en las excavaciones arqueológicas en Ampurias. En 1959 se crea el Instituto de Prehistoria y Arqueología de la Diputación de Barcelona, dando un nuevo impulso a la Arqueología barcelonesa.

El cambio de rumbo en los estudios prehistóricos queda bien reflejado cuando a mediados de los años 50 se suprime la Comisaría General de excavaciones, creándose en su lugar un Servicio Nacional de Excavaciones Arqueológicas, que seguirá dirigiendo Santa-Olalla hasta 1961. La diferencia no era sólo de denominación. De este servicio dependían las Delegaciones Arqueológicas de zona, a cuyo frente estaría un catedrático de universidad. Poco a poco los catedráticos universitarios pasarán a tener mayor peso en la gestión arqueológica lo que redundará en una mayor profesionalización y especialización.

El Congreso de la UISPP de Madrid de 1954 fue presidido por Luis Pericot, siendo su secretario Antonio Beltrán. Este congreso indica, en Arqueología, el nuevo posicionamiento internacional de régimen de Franco tras el inicio de la Guerra Fría. A partir de 1950 había empezado a suavizarse el bloqueo diplomático internacional a España, lo que facilitaría su admisión en la ONU al año siguiente del congreso, en 1955. Este IV Congreso de la UISPP se celebró en Madrid, tras designarse así en las sesiones del III Congreso celebrado en Zúrich en 1950. En las actas, el contenido de uno de los trabajos, el de Santiago Alcobé (1903-1977), resulta muy significativo observar lo poco que se había hecho en España sobre el Paleolítico tras la Guerra Civil. Alcobé (1954) hace una relación de los más importantes yacimientos y ni uno sólo es de nueva excavación de los veinte años previos, pues todos ya se habían excavado antes. Según el programa del congreso, la excursión del mismo fue "a los yacimientos cuaternarios del Manzanares", es decir, en este caso, nada nuevo desde el siglo XIX. En estos años, se forjarán las estructuras y personalidades en Arqueología que estarán vigentes en el siguiente cuarto de siglo. Así, por ejemplo, tal y como mencionamos anteriormente, en 1954 Francisco Jordá Cerdá obtendrá en título de Doctor con su tesis El Solutrense en España y sus problemas, que mantendrá su plena validez hasta finales del siglo $X X$, siendo de obligada referencia al tratar del Solutrense en España.

EI V Congreso del Cuaternario Ilevado a cabo por la International Union for Quaternary Science (INQUA) en 1957, va a dinamizar los estudios sobre el Paleolítico en España. INQUA se había creado en 1928 con el propósito de potenciar y facilitar la investigación científica sobre el Cuaternario en todas las disciplinas. En este congreso, realizado en Madrid y Barcelona en 1957, se volvieron a visitar las terrazas del Manzanares, añadiendo también las del Jarama. Además, con motivo del congreso, se adecentó la Sala de Prehistoria del Museo de Ciencias Naturales (Aguirre, 1993:115), ya que este museo poseía una rica colección de objetos prehistóricos. La excursión $\mathrm{n}^{\circ} 2$ versó sobre El Cuaternario en la Región Cantábrica, y en ella participaron, ente otros, los geólogos Francisco Hernández-Pacheco (1899-1976) y Noel Llopis Lladó (1911-1968) y el prehistoriador Francisco Jordá Cerdá (1914-2004). Las actas se publicaron muchos años más tarde, en 1969, en edición preparada por Emiliano Aguirre (1925-presente).

El año de 1959 se decretó el Plan Nacional de Estabilización Económica que puso las bases del desarrollo económico de los sesenta y principios de los setenta. Con el regreso de algunos exiliados se fue creando de nuevo el caldo de cultivo para retomar las excavaciones que habían sido abandonadas con la Guerra Civil y el triunfo de Franco. Un ejemplo es el regreso de José Miguel de Barandiarán, que en 1953 regresó a Atáun y en 1956 ya había reiniciado excavaciones en Lezetxiki (Mondragón) y en 1960 en Aitzbitarte IV (Errenteria).

Un cambio en los estudios sobre el Paleolítico español se produjo cuando se retoman las excavaciones en Torralba y Ambrona, esta vez dirigidas por Francis Clark Howell (1925-2007) entre 1962 y 1963. Tras los contactos establecidos entre Pericot y Howell en los congresos Panafricanos de Prehistoria, Howell diseñó un plan de excavaciones sistemáticas en estos yacimientos sorianos que en aquellos momentos resultaba novedoso (Santonja et al., 2014: 517), en una excavación en la que colaboraba Emiliano Aguirre.

Si a los años 60 se les podría considerar como de consolidación de la Arqueología española, ya desde comienzos de los años 70 se puede considerar que es la del desarrollo, expansión (Ruiz Zapatero, 1993: 51) y de su definitiva institucionalización. Nuevas cátedras, aumento de necesidades de profesorado y un 
crecimiento exponencial del alumnado facilitarán ese desarrollo. Asimismo muchos museos provinciales contarán con programas de investigación propios.

En el año 1972 se fundó el Grupo Español de Trabajo del Cuaternario (GETQ), cuyo objetivo era el "estudio de la evolución de la tierra desde 2 millones de años atendiendo los sistemas geológicos y biológicos incluyendo el estudio del hombre y la evolución de su cultura". En 1985, el GETQ se reestructuró y pasó a denominarse Asociación Española para el Estudio del Cuaternario (AEQUA), que asumió íntegramente los objetivos del GETQ.

\section{A modo de conclusión}

En 1975 muere Franco y se inicia en España la transición democrática. La Constitución de 1978 tendrá un carácter descentralizado, donde se dará a luz el estado de las autonomías, que asumirán las competencias en la administración de la Arqueología en su territorio. Al mismo tiempo, la imitación del modelo científico americano, donde prima la privatización ha traído consigo el desmantelamiento de buena parte de lo público y la progresiva privatización. $Y$ eso ha tenido especial repercusión en la Arqueología (Estévez and Vila, 2006:118).

La multidisciplinaridad se impone y a diferencia de lo que sucedía durante el siglo XIX, o en la primera mitad del siglo $X X$, en que los naturalistas serán quienes lleven a cabo los estudios prehistóricos, a partir de 1975 será toda una pléyade de científicos, los que, provenientes de las más diversas áreas de conocimiento, unirán sus esfuerzos para conseguir un conocimiento holístico del yacimiento arqueológico y conseguir así una comprensión lo más completa posible de los modos de vida y evolución social de los grupos humanos en estudio.

Para llevar a cabo esa multidisciplinaridad surgirán nuevas corrientes teóricas como el Estructuralismo, el Materialismo Histórico, la Escuela Paleoeconómica, la Arqueología Evolucionista y la Nueva Arqueología, que tendrán amplia representación en la práctica arqueológica española. En este contexto, la Geoarqueología, que acababa de nacer, alcanzará amplia difusión en el último cuarto del siglo $X X$, en prácticamente todas las comunidades autónomas (Jordá Pardo, 1994).

\section{Referencias}

Aguirre, E. 1993. Paleontología humana y Prehistoria en el Museo de Ciencias Naturales. In: Martínez Navarrete, M.
I. (coord.), Teoría y Práctica de la Prehistoria: Perspectivas desde los extremos de Europa, 103-127.

Alcobé, S. 1954. Guía para el estudio antropológico de las poblaciones prehistóricas de España. Actas del IV Congreso Internacional de Ciencias Prehistóricas $y$ Protohistóricas, I, Madrid, 1-48.

Alsius, P. 1871. Breu ensaig geológich de la conca de Banyolas. La Renaxensa, 21, 261-263.

Altuna, J. 1990. D. José Miguel de Barandiarán. In: Gure lehen urratsak. 1990. Odisea en el pasado. Eusko Kultur Eragintza Etor, S.A. San Sebastián, 1-24.

Anónimo 1929. El Servicio de Investigación Prehistórica y su Museo de Prehistoria. Imp. Casa de Beneficencia, Valencia.

Ayarzagüena, M. 1989. Pere Alsius y Torrent, prehistoriador. Espacio, Tiempo y Forma, Serie I, Prehistoria y Arqueología, 2, 433-441.

Ayarzagüena, M. 2002. El yacimiento de San Isidro y los primeros estudios prehistóricos de campo realizados en España (1863-1893). Zona Arqueológica, 1, 18-45.

Ayarzagüena, M. 2004. Prehistoria. In: Bernárdez, M.J. y Guisado, J.C, (eds.), Fondos Arqueológicos del Museo Histórico Minero D. Felipe de Borbón y Grecia. Escuela Técnica Superior de Ingenieros de Minas, Madrid, 17-40.

Ayarzagüena, M. and López, J.F. 2007. Enrique Eguren y Bengoa. Gazseha, 4, 7-17.

Ayarzagüena, M. and Puche, O. 2012. La llamada 'Edad del Cobre' en el siglo XIX. Aportaciones de Casiano de Prado y Juan Vilanova y Piera. Boletín Geológico y Minero, 123, 157-171.

Becerra, J.M. 2000. La legislación española sobre Patrimonio Histórico, origen y antecedentes. La Ley de Patrimonio Histórico Andaluz. Actas de las $V$ Jornadas sobre Historia de Marchena. El Patrimonio y su conservación. Marchena, 9-30.

Berwick y Alba, Duque de (dir.) 1931. Catálogo Histórico y Bibliográfico de la Exposición Internacional de Barcelona 1929-1930, tomo I. Madrid.

Carrera, E. and Martín, A. 1997. Las Instituciones Arqueológicas del Ayuntamiento de Madrid (1924-1972). In: Mora, G. and Díaz-Andreu, M. (eds.), La cristalización del pasado: génesis y desarrollo del marco institucional de la Arqueología en España. Universidad de MálagaCSIC, Málaga, 581-592.

Cartailhac, E. 1902. Les cavernes ornées des dessins. La grotte d'Altamira, Espagne. 'Mea culpa' d'un sceptique. L'Anthropologie, XIII, 348-354.

Cartailhac, E. and Breuil, H. 1906. La Caverne d'Altamira a Santillane prés Santander (Espagne). Imprimerie de Monaco, Mónaco.

Cazurro, M. 1929. El Cuaternario y las estaciones de la época paleolítica en Cataluña. Memoria leída por el académico electo D. Manuel Cazurro y Ruiz en el acto de su recepción y discurso de contestación por el académico numerario D. Luis Mariano Vidal. Memorias de la Real Academia de Ciencias y Artes de Barcelona, $3^{a}$ época. Barcelona.

Cortadella, J. 2003. Historia de un libro que se sostenía por sí mismo: la Etnología de la Península Ibèrica de Pere Bosch Gimpera. In: Bosch, P. (ed.), Etnologia de la 
Ayarzagüena Sanz, M., 2018. El papel desempeñado por geólogos e ingenieros de... Boletín Geológico y Minero, 129 (1/2): 13-33

Península Ibèrica, VII-CCXLIV. Urgoiti Ediciones. Pamplona.

Díaz-Andreu, M. 1997. Prehistoria y Franquismo. In: Mora, G. and Díaz-Andreu, M. (eds.), La cristalización del pasado: génesis y desarrollo del marco institucional de la Arqueología en España. Universidad de Málaga-CSIC, Málaga 547-552.

Estévez, J. and Vila, A. 2006. Una historia de la investigación sobre el Paleolítico en la Península Ibérica. Editorial Síntesis, Madrid.

Genera, M. 2005. La investigación del Paleolítico Inferior en Cataluña: 30 años después de su reconocimiento científico. In: Cabrera, V. and Ayarzagüena, M. (eds.), El nacimiento de la Prehistoria y de la Arqueología científica. Sociedad Española de Historia de la Arqueología, Editorial Arráez Mojácar (Almería), 195-208.

Goldberg, P. and Macphail, R. 2006. Practical andTheoretical Geoarchaeology. Blackwell, Oxford.

Góngora, M. de 1868. Antigüedades prehistóricas de Andalucía. Madrid.

Gràcia, F. 2011. Pere Bosch Gimpera. Deconstruyendo un mito para establecerlo de nuevo. Cercles. Revista d'història cultural, 14, 173-200.

Gràcia, F. and Fullola, J.M. 2006. El sueño de una generación. El crucero universitario por el Mediterráneo de 1933. Edicions Universitat de Barcelona, Barcelona.

Graells, M.P. 1897. Fauna Mastodológica Ibérica. Memoria presentada a la Real Academia de Ciencias Exactas, Físicas y Naturales de Madrid, Madrid.

Hernández-Pacheco, E. 1916. Nomenclatura de voces técnicas y de instrumentos típicos del Paleolítico. Comisión de Investigaciones Paleontológicas y Prehistóricas, Memoria $\mathrm{n}^{\circ}$ 10, Museo de Ciencias Naturales, Madrid.

Hernández-Pacheco, E. 1956. Observaciones respecto a métodos y resultados del estudio de los yacimientos prehistóricos del solar hispano. In: Libro Homenaje al Conde de la Vega del Sella. Memorias del Servicio de Investigaciones Arqueológicas, I, Diputación Provincial de Asturias. Oviedo, 35-46.

Hernández-Pacheco, E. 1959. Prehistoria del Solar Hispano. Orígenes del arte pictórico. Real Academia de Ciencias Exactas, Físicas y Naturales, t. XX de la serie de memorias. Madrid.

Jordá Pardo, J.F. 1994. La Geoarqueología en España hoy. Trabalhos de Antropologia e Etnologia, 34 (3-4), 465-478.

Jordá Pardo, J.F. 2006-2009. Geoarqueología, de la teoría a la práctica: interpretación de un yacimiento de la Edad del Hierro en la Península lbérica. Xama, 19-23, 45-61.

López-Ocón, L. 2010, La Junta para Ampliación de Estudios e Investigaciones Científicas y su proyección europeísta. In: Olmos, R., Tortosa, T. and Bellón, J.P. (eds.), Repensar la Escuela del CSIC en Roma. Cien años de Memoria. Consejo Superior de Investigaciones Científicas, Madrid, 161-174.

Machado, A. 1869. Congreso Internacional de Antropología Prehistórica, Revista de Filosofía, Literatura y Ciencias de Sevilla, I, 33-39 y 281-287.

Madariaga, B. 1972. Hermilio Alcalde del Río. Una Escuela de Prehistoria en Santander. Patronato de las Cuevas Prehistóricas de Santander, Santander.
Martín, A. 2001. Pérez de Barrada y los orígenes de la institucionalización de la arqueología madrileña. Estudios de prehistoria y arqueología madrileñas, 11, Número Homenaje a José Pérez de Barradas, 5-22.

Mederos, A. 2010-2011. Hugo Obermaier, el duro camino hacia la cátedra de historia primitiva del hombre (18771922). Boletín de la Asociación Española de Amigos de la Arqueología, 46, 237-261.

Moure, A. 2006. Escritos sobre historiografía y patrimonio arqueológico. Servicio de Publicaciones de la Universidad de Cantabria. Santander.

Obermaier, H. 1925. El Hombre Fósil. $2^{a}$ edición refundida y ampliada. Comisión de Investigaciones Paleontológicas y Prehistóricas, Memoria $\mathrm{n}^{\circ}$ 9, Museo Nacional de Ciencias Naturales. Madrid.

Pelayo, F. 1999. Ciencia y creencia en España durante el siglo XIX. Departamento de Historia de la Ciencia, Consejo Superior de Investigaciones Científicas, Madrid.

Pelayo, F. and Gozalo, R. 2012. Juan Vilanova y Piera (18211893), la obra de naturalista y prehistoriador valenciano. La donación Masiá Vilanova en el Museo de Prehistoria de Valencia. Serie de Trabajos Varios, $n^{\circ} 114$, Servicio de Investigación Prehistórica del Museo de Prehistoria de Valencia, Diputación de Valencia, Valencia.

Peña, J.L., Sancho Marcén, C., Rubio Fernández, V. and Longares Aladrén, L.A. 2005. Aportaciones desde la Geomorfología y la Geoarqueología al conocimiento de los Paleoambientes Holocenos del NE de España. Actas $X$ Coloquio Ibérico de Geografía. Évora, Portugal.<< http://www.apgeo.pt/files/docs/CD_X_Coloquio_Iberico_ Geografia/pdfs/077.pdf $>>$

Pérez, J. 1929. Los yacimientos prehistóricos de los alrededores de Madrid. Boletín del Instituto Geológico de Madrid LI, XI de la tercera serie, 153-322.

Pollard, A. M. (ed.) 1999. Geoarchaeology: exploration, environments, resources. Geological Society, Special Publications, London, 165, 7-14.

Polo, A. 2007-2008. Geoarqueología y reconstrucción de contextos arqueológicos: contribución y nuevas perspectivas desde el Área de Prehistoria de la Universidad del País Vasco. Veleia, 24-25, 689-700.

Prado, C. de. 1864. Descripción Física y Geológica de la Provincia de Madrid, Imprenta Nacional, Madrid.

Prado, C. de. 1865. Circular de la Comisión Permanente de Geología Industrial, dirigida a los ingenieros de minas, Jefes de las Provincias, Revista Minera, XVI (357), 225236.

Prado, O. 1997. El Seminario de Estudos Galegos: génesis, aportación y desaparición. In: Mora, G. and DíazAndreu, M. (eds.), La cristalización del pasado: génesis y desarrollo del marco institucional de la Arqueología en España. Universidad de Málaga-CSIC, Málaga, 457-461.

Puche, O. and Ayarzagüena, M. 1997. Ingenieros de minas arqueólogos. La huella de Prado. Homenaje a Casiano de Prado (1797-1866) en el bicentenario de su nacimiento. Boletín Geológico y Minero, 108 (3), 79-99.

Quesada, J.M. 2005. El árbol de la ciencia. Escuelas de la Arqueología prehistórica y protohistórica española durante el primer tercio del siglo XX. In: Cabrera, V. y Ayarzagüena, M. (eds.), El nacimiento de la Prehistoria y 
de la Arqueología científica. Sociedad Española de Historia de la Arqueología. Editorial Arráez, Mojácar (Almería), 178-182.

Rábano, I. 2006. Casiano de Prado y Manuel Fernández de Castro: relación epistolar ente 1859 y 1866, Boletín Geológico y Minero, 117 (3), 423-440.

Rasilla, M. de la 1997. La Comisión de Investigaciones Paleontológicas y Prehistóricas y la Arqueología Prehistórica en España (1913-1935). In: Mora, G. and Díaz-Andreu, M. (eds.), La cristalización del pasado: génesis y desarrollo del marco institucional de la Arqueología en España. Universidad de Málaga-CSIC, Málaga, 431-438.

Renfrew, A. C. 1976. Introduction. In: Davidson, D.A. and M.L. Shackley (eds.), Geoarchaeology: Earth Science and the Past. Duckworth, London, 1-5,.

Ruiz-Zapatero, G. 1993. La organización de la arqueología en España. In: Martínez, M.I. (coord.). Teoría y Práctica de la Prehistoria: Perspectivas desde los extremos de Europa, 45-73.

Shackeley, M. I. 1975. Archaeological sediments. A survey of analytical methods. A Halsted Press Book. John Wiley and Sons. New York, Toronto.

Sánchez, L.A. 1990. La Sociedad Española de Antropología, Etnoghrafía y Prehistoria (1921-1951). Revista de Dialectología y Tradiciones Populares, XLV, 61-87.

Santonja, M., Pérez, A. and Flores, R. 2005. Torralba, Ambrona y el Marqués de Cerralbo. Las dos primeras excavaciones del Paleolítico Inferior en España, Zona Arqueológica, 5, 18-39.

Santonja, M., Pérez-González, A., Panera, J., Rubio-Jara, S., Sesé, C., Soto, E. and Sánchez-Romero, L. 2014. Los yacimientos arqueo-paleontológicos de Ambrona y Torralba (Soria). In: Sala, R. (ed.), Los cazadores recolectores del Pleistoceno y del Holoceno en Iberia y el Estrecho de Gibraltar: Estado actual del conocimiento del registro arqueológico. Universidad de Burgos-Fundación Atapuerca, Burgos, 517-527.

Sequeiros, L. 2011. Geología y heterodoxia. La Vindicación de la Geología de Casiano de Prado. Córdoba.

Siret, L. 2001. España Prehistórica. Facta non verba. Arráez Editores, Mojácar (Almería).

Vernet, J. 1975. Historia de la Ciencia Española. Instituto de España, Cátedra "Alfonso X El Sabio", Madrid

Verneuil, E. and Lartet, L. 1863. Note sur un silex taillée trouvé dans le diluvium des environs de Madrid. Bulletin de la Société Géologique de France, $2^{\text {éme }}$ série, XX, 698-702.

Vincent, J. M. 1993. Departamento de Prehistoria del Centro de Estudios Históricos (CSIC). In: Martínez, M.I. (coord.), Teoría y Práctica de la Prehistoria: Perspectivas desde los extremos de Europa, 19-35.

Vilanova, J. 1872. Origen, Naturaleza y Antigüedad del Hombre. Imp. de la Cía. de impresores y Libreros del Reino, Madrid.

Vilanova, J. and Rada, J. D. 1891. Geología y protohistoria ibéricas. El Progreso Editorial. Madrid

Recibido: mayo 2015

Revisado: diciembre 2015

Aceptado: enero 2016

Publicado: marzo 2018 
